\title{
Recent insights into the function of autophagy in cancer
}

\author{
Ravi Amaravadi, ${ }^{1,2}$ Alec C. Kimmelman, ${ }^{3,4}$ and Eileen White ${ }^{5,6}$ \\ ${ }^{1}$ Abramson Cancer Center, ${ }^{2}$ Department of Medicine, Perelman School of Medicine, University of Pennsylvania, Philadelphia, \\ Pennsylvania 19104, USA; ${ }^{3}$ Perlmutter Cancer Center, ${ }^{4}$ Department of Radiation Oncology, New York University Langone \\ Medical Center, New York, New York 10016, USA; ${ }^{5}$ Rutgers Cancer Institute of New Jersey, New Brunswick, New Jersey 08903, \\ $\mathrm{USA}_{;}{ }^{6}$ Department of Molecular Biology and Biochemistry, Rutgers University, Piscataway, New Jersey 08854, USA
}

\begin{abstract}
Macroautophagy (referred to here as autophagy) is induced by starvation to capture and degrade intracellular proteins and organelles in lysosomes, which recycles intracellular components to sustain metabolism and survival. Autophagy also plays a major homeostatic role in controlling protein and organelle quality and quantity. Dysfunctional autophagy contributes to many diseases. In cancer, autophagy can be neutral, tumor-suppressive, or tumorpromoting in different contexts. Large-scale genomic analysis of human cancers indicates that the loss or mutation of core autophagy genes is uncommon, whereas oncogenic events that activate autophagy and lysosomal biogenesis have been identified. Autophagic flux, however, is difficult to measure in human tumor samples, making functional assessment of autophagy problematic in a clinical setting. Autophagy impacts cellular metabolism, the proteome, and organelle numbers and quality, which alter cell functions in diverse ways. Moreover, autophagy influences the interaction between the tumor and the host by promoting stress adaptation and suppressing activation of innate and adaptive immune responses. Additionally, autophagy can promote a cross-talk between the tumor and the stroma, which can support tumor growth, particularly in a nutrient-limited microenvironment. Thus, the role of autophagy in cancer is determined by nutrient availability, microenvironment stress, and the presence of an immune system. Here we discuss recent developments in the role of autophagy in cancer, in particular how autophagy can promote cancer through suppressing p53 and preventing energy crisis, cell death, senescence, and an anti-tumor immune response.
\end{abstract}

The core autophagy machinery is encoded by autophagyrelated $(A T G)$ genes, of which there are now $>30$ (Ktistakis and Tooze 2016). These genes and their protein products are regulated by numerous upstream signals, including nutrient availability, stressors, defective organelles, and

[Keywords: autophagy; ATG; cancer; mouse models; chloroquine] Corresponding author: eileenpwhite@gmail.com

Article is online at http://www.genesdev.org/cgi/doi/10.1101/gad.287524. 116. pathogenic conditions. ATG gene products control the formation of the hallmark double-membrane vesicle, the autophagosome. Other genes encode cargo receptors that direct the cargo to the forming autophagosome. Control of the trafficking machinery then orchestrates fusion of the cargo-laden autophagosomes with lysosomes. Degradative enzymes, contributed by lysosomes, break down the cargo, and the products are exported into the cytoplasm, where they are recycled into metabolic and biosynthetic pathways (Rabinowitz and White 2010; Guo et al. 2016). Under normal nutrient conditions, autophagy functions at a constitutive, low basal level to maintain protein and organelle quality, quantity, and functionality. The ATG genes and autophagy are dramatically induced by starvation and other stressors, which enable cellular and organismal survival. Up-regulation of autophagy is a means to survive nutrient stress, which is conserved from yeast to mammals. More recently, there is a growing appreciation of the role played by ATG genes in modulating intracellular trafficking, endocytosis, exocytosis, macropinocytosis, and exosome production (White 2013; Baixauli et al. 2014; Ponpuak et al. 2015).

Core autophagy genes are generally not mutated in cancer

Early evidence suggested that BECN1 (ATG6) was a tumor suppressor gene. This was based on reports that one allele of $B E C N 1$ was lost with high frequency in breast, ovarian, and prostate cancer; that BECN1 overexpression suppressed human breast cancer cell line growth; and that mice with allelic loss of Becn 1 are tumor-prone (Aita et al. 1999; Liang et al. 1999; Qu et al. 2003; Yue et al. 2003). However, $B E C N 1$ is adjacent to the known tumor suppressor gene breast cancer 1 (BRCA1) on chromosome 17.

Hereditary breast cancer commonly results from the presence of a pathogenic germline missense mutation in $B R C A 1$ (or BRCA2 or PALB2) followed by somatic

(C) 2016 Amaravadi et al. This article is distributed exclusively by Cold Spring Harbor Laboratory Press for the first six months after the full-issue publication date (see http://genesdev.cshlp.org/site/misc/terms.xhtml). After six months, it is available under a Creative Commons License (Attribution-NonCommercial 4.0 International), as described at http:// creativecommons.org/licenses/by-nc/4.0/. 
deletion of the remaining wild-type $B R C A 1$ allele. These deletions are typically large, deleting $B R C A 1$ along with hundreds of other genes, including BECN1. Genomic analysis of BECN1 in The Cancer Genome Atlas (TCGA) demonstrated that allelic loss of BECN1 does not occur independently of codeletion with $B R C A 1$, suggesting that $B R C A 1$ loss is the driver mutation in hereditary and sporadic breast cancer (Laddha et al. 2014; White et al. 2015). Moreover, recurrent somatic mutations that are a hallmark feature of tumor suppressor genes are not found in BECN1 in human cancers (Aita et al. 1999; Laddha et al. 2014). Less BECN1 expression resulting from concurrent BECN1 and BRCA1 deletion (Laddha et al. 2014; Tang et al. 2015), however, may reduce autophagy in these cancers, which may impair their response to stress and nutrient deprivation that may be therapeutically exploitable.

Insight into the role of autophagy in human cancer is also provided by a more global analysis of the mutational status of the genes encoding the entire core autophagy machinery in TCGA. The core autophagy machinery is generally not targeted by high-frequency somatic singlenucleotide mutations across cancers in TCGA (Lebovitz et al. 2015). Although a small number of recurrent mutations in RB1CC1/FIP200, ULK4, and ATG7 are found, these are rare and limited to few tumor types. These large-scale analyses indicate that the core autophagy machinery largely escapes genomic mutation in human cancers. It will be interesting to explore the significance of the minority of tumors in which these rare mutations are found.

Analysis of the human cancer transcriptomes indicates largely invariable ATG gene expression (Lebovitz et al. 2015). This suggests a pattern of sustained transcriptional expression similar to genes unable to tolerate reduced expression in cancer. As such, the core autophagy machinery is expressed and may be protected from alteration in the majority of human cancers (Lebovitz et al. 2015). It is also interesting to note that the microphthalmia/TFE (MiTF/TFE) subfamily of basic helix-loop-helix leucine zipper transcription factors that promote autophagy and lysosomal biogenesis is encoded by oncogenes (Ferguson 2015), which may contribute to expression of the autophagy pathway in human cancers. Thus, the majority of human cancers expresses a functionally intact autophagy pathway, and, in a subset of these, the pathway is transcriptionally up-regulated.

\section{Regulation of core autophagy genes and cargo receptors in cancer}

The first complex known to regulate autophagy is the ULK1-ATG13-FIP200 complex (Ganley et al. 2009). ATG13 and ULK1 are phosphorylated and inhibited by mTOR in a nutrient-dependent fashion to regulate autophagy initiation. Recent work revealed a direct interaction between focal adhesion (FA) kinase (FAK) familyinteracting protein of $200 \mathrm{kDa}$ (FIP200) and ATG16L1 (a component of the ATG12-ATG5-ATG16L1 complex), which is crucial for ULK1 complex-dependent autophagy independent of ULK1 kinase activity (Gammoh et al. 2013). Intriguingly, amino acid starvation can engage a protein phosphatase (PP2A-B55a) to efficiently dephosphorylate and activate the ULK1 complex. This finding explains a puzzling observation in the field: Nutrient starvation triggers autophagy more rapidly than rapamycin despite the fact that both nutrient starvation and rapamycin suppress mTORC1 activity equally well. It also reveals one possible mechanism accounting for the high basal autophagy activity in "autophagy-addicted" cancer cells. The seemingly contradictory coexistence of intact mTORC1 function and strong autophagy activity in cancer cells may be due to the expression of phosphatase activity targeting ULK1, which offsets the autophagy inhibitory function of $\mathrm{mTORC1}$, allowing cancer cells to simultaneously reap the benefits of both mTOR signaling and autophagy activation (Wong et al. 2015).

Independent of its well-characterized role in autophagy, FIP200 interacts with other proteins to regulate diverse cellular functions (Gan and Guan 2008). To address potential contributions of its autophagy-dependent and autophagy-independent action in cancer, a Fip200 conditional knock-in mutant allele (cKI) was generated that specifically disrupts FIP200 interaction with its autophagy partner, ATG13, to block autophagy but not its binding to other cell signaling molecules. Changing residues 582585 (LQFL) to AAAA (FIP200-4A mutant) in FIP200 demonstrates that this region is required for interaction with ATG13 and abolishes its canonical autophagy function in vitro. Specifically blocking FIP200 interaction with ATG13 using FIP200-4A mutant knock-in mice prevents autophagy in vivo, providing direct support for the essential role of the ULK1/ATG13/FIP200/ATG101 complex in the process beyond previous studies that knock out individual components. The nonautophagic functions of FIP200 (for instance, promoting resistance to TNF- $\alpha$-induced apoptosis) are retained in this cKI model, as embryogenesis is unaffected, unlike FIP200 knockout mice. However, FIP200-mediated canonical autophagy is required to support neonatal survival and tumor cell growth (Chen et al. 2016).

Selective autophagy provides a means to control the turnover of specific proteins and organelles in a signal-dependent manner. However, our understanding of these systems and how cargo is selected is rudimentary. Recently, progress has been made in elucidating the identity and regulation of cargo receptors for degradation of ferritin (ferritinophagy) and damaged mitochondria (mitophagy). While mitophagy employs a ubiquitin signal on damaged mitochondria to link with the autophagy cargo receptors OPTN and NDP52, ferritin is recognized by a new adaptor (NCOA4), which localizes to autophagosomes and is required for delivery of ferritin to the lysosome, where iron is released for use by the cell (Dowdle et al. 2014; Mancias et al. 2014). The expression of NCOA4 itself is regulated by iron. In a high-iron milieu, NCOA4 associates with the HERC2 ubiquitin ligase and is degraded, while, in a low-iron milieu, NCOA4 accumulates and delivers ferritin to the autophagosome. NCOA4 is required 
for erythropoiesis in vertebrates (Mancias et al. 2015). Future work will uncover the role of other cargo receptors and the six ATG8 proteins in the control of selective autophagy. Additionally, with the realization that the regulated expression of specialized cargo receptors allows the cell to promote one type of selective autophagy over another (Green and Levine 2014), it is also timely to consider how one can exploit inactivation of such selective adaptor proteins to parse out the different roles of autophagy in cancer to determine whether specific types of autophagy play more significant roles than others in tumorigenesis (Mancias and Kimmelman 2016).

The autophagy cargo receptor p62/SQSTM1 binds ubiquitin on cargo to deliver cargo to autophagosomes by docking onto microtubule-associated protein $1 \mathrm{~A} / 1 \mathrm{~B}$ light chain 3 (LC3) on autophagosomes. P62 itself is an autophagy substrate that accumulates when autophagy is inhibited (Katsuragi et al. 2015). p62 accumulation induced by autophagy inactivation contributes to the development of benign hepatomas in mouse models, but the underlying mechanism is not known (Komatsu et al. 2007; Takamura et al. 2011). In addition to its role as a cargo adapter, p62 also serves as a signaling adaptor for TRAF6, KEAP1, and components of the mTORC1 complex, promoting survival and proliferative functions, possibly explaining the tumor promotion observed upon its accumulation. In support of this concept, accumulation of $\mathrm{p} 62$ has been observed in premalignant liver disease, and high expression of p62 in hepatocellular carcinoma (HCC) predicts poor prognosis (Umemura et al. 2016). In multiple physiologically relevant HCC mouse models, p62 is necessary for the activation of mTORC1 in HCCs driven by TSC2 deficiency (Umemura et al. 2016). A role for p62 in promoting NFR 2 activation and HCC has also been identified (Saito et al. 2016). Adenovirus-mediated overexpression of p62 in hepatocytes in vivo in the absence of any other oncogenic stimuli drives HCC through the activation of mTORC1 in a manner that is independent of p62's role as a cargo receptor in autophagy. These results establish for the first time that the ability of p62 to activate mTORC1 (along with NRF2) in hepatocytes in vivo is a new critical driver of liver cancer initiation (Umemura et al. 2016). In contrast, reduction of p62 in stroma promotes tumorigenesis of prostate cancer through interleukin-6 (IL6) production (Valencia et al. 2014). Roles of other cargo receptors in cancer have also been reported. Sequestration of the cargo receptor NDP52 promotes noncanonical nuclear factor $\mathrm{\kappa B}(\mathrm{NF}-\mathrm{\kappa B})$ signaling in cancer cells (Newman et al. 2012), and ubiquitylation of the cargo receptor OPTN increases autophagy and p62 elimination, suppressing tumorigenesis (Liu et al. 2014). Thus, the cargo receptors whose levels are controlled by autophagy can play a role in cancer.

Given the recent appreciation for the importance of mitochondria in cancer (Zong et al. 2016), a selective form of autophagy of particular interest is that of mitophagy, which removes damaged mitochondria. Emerging findings indicate that there are multiple mechanisms by which mitochondria can be targeted for degradation at the autophagolysosome (Chourasia et al. 2015a). Elimina- tion of depolarized mitochondria by mitophagy depends on the action of the PINK1 kinase and its ability to recruit the PARKIN E3 ubiquitin ligase that promotes ubiquitination of key mitochondrial proteins, which serve as "eat me" signals to cargo receptors targeted by nascent autophagosomes (Youle and Narendra 2011; Lazarou et al. 2015). Not all mammalian cells express high levels of PARKIN; therefore, there is an ongoing search for other mitophagy regulators, especially in cancer cells. Additional PARKIN-independent mitophagy adaptors include BCL2/adenovirus E1B 19-kDa-interacting protein 3 (BNIP3), BNIP3L/NIX, and FUN14 domain-containing protein 1 (FUNDC1) that are induced by specific developmental signals and physiological stresses (for example, hypoxia, nutrient deprivation, loss of the tumor suppressors $\mathrm{p} 53$ or $\mathrm{pRB}$, and activation of NF- $\mathrm{kB}$ or FoxO transcription factors). These mitophagy adaptors interact directly with processed LC3 and promote an overall reduction in mitochondrial mass as an adaptive response to stresses (Novak et al. 2010; Hanna et al. 2012; Liu et al. 2012; Chourasia et al. 2015a). BNIP3, a BH3 domain-containing protein that, in some contexts, is considered a proapoptotic protein, likely plays a more important role in mitophagy than in the regulation of apoptosis during nutrient stress. BNIP3 is induced by nutrient deprivation in the liver, where it plays a role in promoting mitophagy and lipid oxidation (Glick et al. 2012). BNIP3 expression is induced during the early stages of tumorigenesis but is lost in advanced cancer (Sowter et al. 2001, 2003; Okami et al. 2004; Abe et al. 2005; Akada et al. 2005; Erkan et al. 2005). Therefore, BNIP3 acts as a tumor suppressor in mouse models (Manka et al. 2005; Chourasia et al. 2015b). Loss of BNIP3 is observed in triple-negative breast cancer (Koop et al. 2009; van Diest et al. 2010; Chourasia et al. 2015b), and mice carrying a targeted deletion of BNIP3 sustain increased rates of tumor growth, acquire invasiveness, and increase spontaneous metastasis (Chourasia et al. 2015b). Tumors in these mice have increased mitochondrial mass but reduced mitochondrial respiration and metabolite uptake. Increased production of reactive oxygen species (ROS) leads to increased hypoxiainducible factor $1 \alpha$ (HIF-1 $\alpha$ ) levels and activity, glycolytic metabolism, and angiogenesis (Chourasia et al. 2015b). Thus, BNIP3, a HIF-1 $a$ target, may act as a tumor suppressor downstream from HIF- $1 \alpha$, feeding back to promote mitochondrial integrity, reduce ROS production, and limit the protumorigenic activity of HIF-1a.

Interestingly, tumor suppressor activity has also been attributed to PARKIN, which is deleted in human ovarian, breast, bladder, and lung cancers among others (Cesari et al. 2003), and this activity is associated with promoting oxidative metabolism (Zhang et al. 2011). Thus, in contrast to inhibition of general autophagy that blocks tumor progression (Wei et al. 2011; Yang et al. 2011; Guo et al. 2013a; Rosenfeldt et al. 2013; Strohecker et al. 2013), genetic deletion of two different mitophagy modulators (PARKIN and BNIP3) leads to increased tumorigenesis and accelerated progression to malignancy (Zhang et al. 2011; Chourasia et al. 2015b). There are a number of major differences between loss of canonical autophagy genes 
and inactivation of specific mitophagy pathways. First, inactivation of BNIP3 does not eliminate all forms of mitophagy and simply reduces stress-induced mitophagy. Perhaps, if all forms of mitophagy are inactivated, this would have a different phenotypic consequence more similar to inhibition of canonical autophagy genes. Note that autophagy supplies substrates for mitochondrial metabolism, the loss of which significantly impairs mitochondrial function beyond what would be expected for loss of mitophagy alone (Guo et al. 2016). In addition, genetic autophagy inhibition produces an accumulation of oncogenic p62, whereas genetic mitophagy inhibition does not, further distinguishing the function of autophagy from mitophagy.

\section{Evidence from mouse models that autophagy suppresses cancer initiation}

A large body of work in genetically engineered mice deficient for essential autophagy genes in specific tissues has demonstrated that autophagy prevents an array of degenerative and inflammatory diseases (Mizushima and Komatsu 2011). The mechanisms by which autophagy is thought to maintain tissue homeostasis include the removal of toxic, unfolded, or mutant proteins and the elimination of damaged mitochondria and other organelles. Connections between metabolic defects and degenerative and inflammatory disease caused by loss of autophagy remain to be explored. Arguably, the disease in which the functional status of autophagy has been investigated the most is cancer.

Despite the predominant absence of genetic inactivation of the core autophagy machinery in human cancers thus far, animal models in which autophagy loss promotes tumorigenesis have been identified. Becn $1^{+/-}$ mice are prone to lung and liver tumors and mammary hyperplasia late in life (Qu et al. 2003; Yue et al. 2003). It is important to note that, in Becn1 ${ }^{+/-}$cells, the expression levels of the tumor suppressor p53 are also significantly reduced, again suggesting that there may be autophagy-independent reasons for the unique ability of the $B e c n 1^{+/-}$ genotype to produce spontaneous tumors compared with other genetic autophagy defects (Liu et al. 2011). For instance, mosaic deletion of Atg5 in mice or Atg7 in mouse livers produces only benign hepatomas, suggesting that complete and specific autophagy deficiency promotes liver tumor initiation but restricts progression to malignant disease (Takamura et al. 2011). Similarly, loss of Atg5 or Atg7 in the mouse pancreas in the setting of a Kras mutation promotes benign pancreatic intraepithelial neoplasia (PanIN) formation but also prevents progression of this PanIN to malignant disease (Rosenfeld et al. 2014; Yang et al. 2014). Autophagy loss in the liver and pancreas causes oxidative stress, chronic tissue damage, and inflammation, all factors that are well known to promote tumor initiation (Mathew et al. 2009). This chronic state of tissue damage, cell death, and inflammation promotes compensatory proliferation, producing cells vulnerable to mutation and oncogenic transforma- tion (White 2012). The situation may be similar in a mouse model of breast cancer in which allelic loss of becn1 promotes expansion of the stem cell pool susceptible to transformation by Wnt pathway activation (Cicchini et al. 2014). However as mentioned above, this may be due to autophagy-independent mechanisms as well (Cicchini et al. 2014).

Another example relating chronic inflammation to loss of autophagy is in Crohn's disease (CD) caused by the ATG16L1 Thr300Ala disease-associated polymorphism. $\mathrm{CD}$ is associated with chronic inflammation of the colon and intestine. Patients with CD are also predisposed to the development of cancer in these areas of inflammation. Atg16L $1^{\text {T300A }}$ knock-in mice manifest the Paneth cell abnormalities associated with CD and also display defects in Goblet cells. Embryonic fibroblasts from these mice surprisingly have only a modest impairment of basal and induced autophagy but rather have a larger defect in autophagy of bacteria and increased production of IL-1 $\beta$ (Lassen et al. 2014). This suggests that the primary problem created by the ATG16L1 Thr300Ala disease-associated polymorphism is one of impaired anti-bacterial host defense, which in turn leads to chronic inflammation, tissue damage, and an elevated cancer risk.

As mentioned above, accumulation of the autophagy cargo receptor and substrate p62 in autophagy-deficient livers promotes tumorigenesis (Komatsu et al. 2007). Accumulation of p62 also promotes lung and mammary tumorigenesis induced by autophagy deficiency (Moscat and Diaz-Meco 2012; Wei et al. 2014). p62 activates NRF2 by binding to its inhibitor, KEAP1 (Komatsu et al. 2010; Lau et al. 2013), and also activates mTOR and NF$\mathrm{\kappa B}$ as discussed above, and its aberrant accumulation in autophagy-deficient tissues can activate these oncogenic signaling pathways. p62 deficiency blunts mammary and lung tumorigenesis and liver tumorigenesis induced by Atg7 loss (Moscat and Diaz-Meco 2012; Wei et al. 2014). In Braf ${ }^{\mathrm{V} 600 \mathrm{E}}$-driven lung tumors, autophagy deficiency transiently stimulates tumor growth by enhancing activation of NRF2, which may be due to accumulation of p62 (Strohecker et al. 2013). Later, these tumors without Atg7 slow their growth and fail to transition from benign to malignant tumors.

The recurring theme from mouse models in which autophagy deficiency promotes tumorigenesis is that autophagy (1) prevents oxidative stress, activation of the DNA damage response, chronic tissue damage, and inflammation and (2) prevents accumulation of the autophagy substrate p62 and promotes activation of mTOR and NRF2. These events are a source of genomic instability and oncogenic signal transduction that promote cancer initiation (Karantza-Wadsworth et al. 2007; Mathew et al. 2007, 2009) commonly found in states of chronic inflammation induced by a broad array of stimuli. With the possible exception of the CD ATG16L1 disease-associated polymorphism, the question of whether this mode of tumor promotion upon suppression of autophagy occurs in humans has not been reported. Indeed, humans with loss of function of core ATG genes and autophagy, as is the situation in these mouse models, have not been 
identified. It is possible that these mechanisms come into play in humans only indirectly, through constitutive activation of mTOR, for example, which inhibits autophagy. Alternatively, autophagy loss may not be relevant to the vast majority of human cancers.

\section{Evidence that autophagy promotes growth of advanced cancer}

A first indication that autophagy may promote cancer came from the observations that autophagy is up-regulated in hypoxic tumor regions, suppresses tumor-induced inflammation, and promotes tumor cell survival (Degenhardt et al. 2006). As the functional status of autophagy is clearly influenced by the tumor microenvironment and the immune system, this revealed the importance of assessing autophagy in genetically engineered mouse models (GEMMs) of cancer. This approach has allowed investigation of whether or not tissue type or cancer genetics influence the role for autophagy in cancer. GEMMs have dissected the tumor cell-autonomous functions of autophagy and provided insight into a therapeutic window for autophagy inhibition in cancer therapy. A summary of the findings from these models is presented in Table 1.

\section{Lung cancer}

One of the most studied models of lung cancer is the GEMM driven by oncogenic Kras. Inhalation of an adenovirus expressing Cre recombinase is used to activate $\mathrm{Kras}^{\mathrm{G} 12 \mathrm{D}}$. Spontaneous non-small-cell lung cancer (NSCLC) arises following Kras activation through a stepwise progression from hyperplasia to adenoma to adenocarcinoma, associated with spontaneous mutation in p53 (Jackson et al. 2001; Johnson et al. 2001). To test the role of autophagy in NSCLC, oncogenic Kras was activated with or without simultaneous deletion of Atg7 in the lungs of mice (Guo et al. 2013a). Epithelial tumor cells within tumors are wild type or deleted for the essential autophagy gene $\operatorname{Atg} 7$ as dictated by the genotype of the mice but in the background of Atg7 wild-type host tissue. These studies established that Atg7 deficiency reduces Kras ${ }^{\mathrm{G} 12 \mathrm{D}}$-driven lung tumor cell proliferation and tumor burden in comparison with mice with tumors where Atg7 is intact (Guo et al. 2013a). Similar results are found with Atg5 deletion, suggesting that this is due to impaired autophagy (Rao et al. 2014). Surprisingly, mice with $A \operatorname{tg} 7^{+/+}$tumors die from cancer, whereas mice with Atg $7^{-/-}$tumors die from inflammatory pneumonia (Guo et al. 2013a), demonstrating that Atg7-deficient lung tumors trigger an immune response. Atg7 deficiency activates $\mathrm{p} 53$, which contributes to tumor suppression, as codeletion of $p 53$ partially rescued tumor growth impairment (Guo et al. 2013a). Thus, Atg7 promotes growth of both Kras-driven p53 wild-type and p53-deficient lung tumors.

A particularly striking finding is that Atg7-deficient Kras-driven tumors accumulate defective mitochondria
(Guo et al. 2013a), which histologically resemble human benign oncocytomas (Gasparre et al. 2011). This suggests that failure of mitochondrial quality control and function may limit the growth and malignancy of Ras-driven lung cancer. Autophagy defects in these Ras-driven tumors causes metabolic impairment that may be the root cause of reduced tumor growth, survival, and malignancy. Without Atg7, tumor cells derived from these mice have impaired mitochondrial respiration and fatty acid oxidation (FAO). These Atg7-deficient tumors and tumor cells accumulate lipids, and tumor cells are sensitive to starvation (Guo et al. 2013a). This suggests that autophagy promotes metabolic robustness and malignancy through maintenance of mitochondrial function and that autophagy inhibition may suppress Kras-driven lung cancers. Interestingly, human renal oncocytomas, which typically lack Ras mutations, have pathogenic mitochondrial genome mutations, respiration defects, energy stress, and defective autophagy and may owe their benign status to similar mechanisms found in Atg7-deficient Ras-driven tumors (Joshi et al. 2015).

If autophagy promotes Kras lung tumorigenesis by conveying metabolic robustness, what is the mechanism? Autophagy eliminates mitochondria by mitophagy, and the vast accumulation of mitochondria is indeed a pronounced phenotype of Atg7-deficient tumors. One hypothesis is that autophagy preserves mitochondrial function by eliminating dysfunctional mitochondria with pathogenic mitochondrial mutations. To test this hypothesis, the mitochondrial genomes of tumors from the Kras-driven GEMM for NSCLC with and without Atg7 were sequenced. While the mitochondrial variant allele frequency was higher in Atg7-deficient tumors, there were too few nonsynonymous mutations, and their frequency was below that of manifestation of mitochondrial dysfunction (Guo et al. 2016). Thus, autophagy does control quality of the mitochondrial genome; however, this is not sufficient to explain the pronounced metabolic defect in tumors and tumor cells upon deletion of Atg7 (Guo et al. 2016).

Another hypothesis is that autophagy captures and degrades intracellular components to provide substrates for mitochondrial metabolism. To test this hypothesis, Atg7 wild-type and Atg7-deficient tumor cell lines from the GEMM for NSCLC were grown in isotope-labeled nutrients to stably label macromolecules. The label was then briefly flushed out of metabolic pathways by chasing with unlabeled medium, and then the tumor cells were challenged with starvation to test for the ability to recycle the stably labeled macromolecules. In comparison with wild type, Atg7-deficient tumor cells had a defective mitochondrial substrate supply, as indicated by less labeled glutamate, a-ketoglutarate, and aspartate and profound depletion of nucleotide pools in starvation (Guo et al. 2016). This defective recycling and substrate supply in Atg7-deficient tumor cells decreased mitochondrial oxygen consumption and increased oxidative stress and energy crisis, which was rescued by glutamine, glutamate, and nucleosides. Thus, a primary function of autophagy in Kras-driven lung cancer is to recycle 
Table 1. Phenotypes of autophagy deficiency in GEMMs for cancer

\begin{tabular}{lll}
\hline Tissue/genotype & \multicolumn{1}{c}{ Phenotype } & References \\
\hline Lung: adenovirus-Cre tumors: & Atg7 deficiency reduces $\mathrm{Kras}^{\mathrm{G} 12 \mathrm{D}}$-driven lung tumor cell proliferation and \\
Kras ${ }^{+12 \mathrm{D}}$ & tumor burden. & Guo et al. 2013a \\
$\mathrm{Atg}^{+/+}$or $A \operatorname{tg} 7^{-/-}$ & Atg7-deficient tumors activate apoptosis and the immune response. \\
& Atg7-deficient tumors accumulate defective mitochondria and pathologically \\
& resemble benign oncocytomas. \\
& Mice with $A \operatorname{tg} 7^{+/+}$tumors die from cancer; mice with $A \operatorname{tg} 7^{-/-}$tumors die \\
& from pneumonia. \\
& Atg7 suppresses p53 activation, which contributes to tumor growth and \\
& progression.
\end{tabular}

Lung: adenovirus-Cre tumors: $\operatorname{Kras}^{\mathrm{G} 12 \mathrm{D}}$ p53 $3^{-/-}$ Atg $7^{+/+}$or $A \operatorname{tg} 7^{-/-}$

Lung: adenovirus-Cre tumors: $\mathrm{Kras}^{\mathrm{G} 12 \mathrm{D}}$ p53 $3^{+/+}$or $p 53^{-/-} \operatorname{Atg}^{+/+}$, Atg $5^{+/-}$ or $\operatorname{Atg} 5^{-/-}$

Lung: adenovirus-Cre tumors: $\mathrm{Braf}^{\mathrm{V} 600 \mathrm{E}}$

Atg $7^{+/+}$or $A \operatorname{tg} 7^{-/-}$

Mouse:

$\mathrm{Nrf2} 2^{+/+}$or $\mathrm{Nrf2}^{-/-}$

Lung: tumors: adenovirus-Cre tumors:

$\mathrm{Braf}^{\mathrm{V} 600 \mathrm{E}}$

p53 ${ }^{-/-}$

Atg $7^{+/+}$or $A \operatorname{tg} 7^{-/-}$

Pancreas: Pdx1-Cre tumors: $\mathrm{Kras}^{\mathrm{G} 12 \mathrm{D}}$

p53 $3^{+/+}$or $p 53^{-/-}$

Atg $^{+/+}$or $\mathrm{Atg}^{-/-}$

Pancreas: Pdx1-Cre tumors:

$\mathrm{Kras}^{\mathrm{G} 12 \mathrm{D}}$

p53 $3^{+/-}$

Atg $^{+/+}$or $\mathrm{Atg}^{-/-}$

Mammary epithelium: MMTVCre tumors:

polyoma middle $\mathrm{T}$ antigen

(PyMT)

Fip2OO $^{+/+}$and Fip200-/-

Mammary epithelium: $\operatorname{Becn} 1^{+/+}$ or Becn1 $1^{+/-}$mice

WAP-Cre tumors:
Atg7 promotes growth of Kras-driven, p53-deficient lung tumors.

Atg7 expression in tumors reduces overall mouse survival.

Atg7-deficient tumors accumulate defective mitochondria and pathologically resemble benign oncocytomas.

Autophagy defects metabolically impair tumor cells: defective mitochondrial respiration and fatty acid oxidation (FAO), lipid accumulation, and sensitivity to starvation.

Autophagy promotes the metabolic robustness and malignancy of Krasdriven lung tumors.

Atg5 deletion increases mouse survival in tumors driven by Kras.

Atg5-deficient tumor cells accumulate abnormal mitochondria and display

evidence of metabolic impairment.

Reduced tumor progression with Atg5 loss.

Anti-tumor activity of Atg5 loss is p53-dependent.

Atg7 deficiency reduces Braf ${ }^{\mathrm{V} 600 \mathrm{E}}$-driven lung tumor cell proliferation and tumor burden and prolongs mouse survival.

Early and transient stimulation of tumor growth by Atg7 deficiency is due to Nrf2 activation.

Atg7-deficient tumors accumulate defective mitochondria and pathologically resemble benign oncocytomas.

Atg7 promotes tumor growth and malignancy by suppressing p53 activation. Atg7 promotes growth of $\mathrm{Braf}^{\mathrm{V} 600 \mathrm{E}}$-driven, p53-deficient lung tumors.

Atg7-deficient tumors accumulate defective mitochondria and pathologically resemble benign oncocytomas.

Autophagy defects cause metabolic impairment: increased oxidative stress, defective mitochondrial respiration, sensitivity to starvation, and glutamine dependence.

Autophagy may supply mitochondrial substrates to maintain lung tumor metabolism.

Autophagy inhibition suppresses Braf ${ }^{\mathrm{V} 600 \mathrm{E}}$-driven lung cancers.

Atg5 or Atg7 deficiency promotes PanIN but blocks progression to pancreatic ductal adenocarcinoma (PDAC).

Autophagy loss promotes $p 53$-dependent limitation of PanIN progression.

Compound $p 53$ deficiency accelerates tumorigenesis with Atg deficiency.

This context of $p 53$ deficiency and Ras activation during embryogenesis does not model human PDAC.

Atg5 deficiency with Kras activation and the stochastic loss of

heterozygosity (LOH) of $p 53$ promotes PanIN formation.

Atg5 loss limits progression of PanIN to PDAC and extends mouse life span.

Atg5 deficiency impairs metabolic fitness and growth independently of p53

status.

Fip200 deficiency in PyMT-driven mammary cancer suppresses tumor

growth and prolongs mouse survival.

Fip200 loss in tumors activates an immune response, interferon production, and lymphocyte infiltration.

T-cell depletion promotes growth of Fip200-deficient tumors.

Targeting Fip200 or the autophagy initiation complex may suppress breast cancer.

Deficiency in the hereditary breast cancer susceptibility gene Palb2

promotes mammary tumorigenesis.

Tumors acquire mutations in $p 53$, and conditional p53 deficiency accelerates
Guo et al. 2013a

Rao et al. 2014

Strohecker et al. 2013

Strohecker et al 2013

Rosenfeldt et al. 2013

Yang et al. 2014

Wei et al. 2011

Huo et al. 2013

Continued 
Table 1. Continued

\begin{tabular}{|c|c|c|}
\hline Tissue/genotype & Phenotype & References \\
\hline $\begin{array}{l}\text { Palb2 } \\
p 53^{+/+} \text {or } p 53^{-/-} \\
\text {Becn1 } 1^{+/+} \text {or Becn1 } 1^{+/-}\end{array}$ & $\begin{array}{l}\text { tumorigenesis driven by Palb2 loss. } \\
\text { Allelic loss of Becn1 suppresses tumorigenesis induced by Palb2 deficiency } \\
\text { and prolongs mouse life span with p53 intact and not with } p 53 \text { deficiency. } \\
\text { p53 is a barrier to mammary cancer development, and autophagy facilitates } \\
\text { cell survival and tumorigenesis. }\end{array}$ & \\
\hline $\begin{array}{l}\text { Melanocytes: Tyr-Cre-ERT2 } \\
\text { tumors: } \\
\text { Braf }^{\mathrm{V} 600 \mathrm{E}} \\
\text { Pten }^{+/+}, \text {Pten }^{+/-}, \text {or } \text { Pten }^{-/-} \\
\text {Atg } 7^{+/+} \text {or Atg } 7^{-/-}\end{array}$ & $\begin{array}{l}\text { Atg7 deficiency reduces Braf }{ }^{\mathrm{V} 600 \mathrm{E}} \text {-driven, Pten-deficient melanoma initiation } \\
\text { and proliferation. } \\
\text { Atg7 prevents oxidative stress, apoptosis, fibrosis, and senescence. } \\
\text { Atg7 deficiency promotes immune cell infiltration and cytokine production. } \\
\text { Atg7 deficiency in melanoma prolongs mouse survival. }\end{array}$ & Xie et al. 2015 \\
\hline $\begin{array}{l}\text { Intestinal epithelium: } \\
\text { Vil-Cre-ERT2 }\end{array}$ & $\begin{array}{l}\text { Adenomatous polyposis coli }(A p c) \text { tumor suppressor loss activates autophagy } \\
\text { and tumorigenesis in the intestinal epithelium. }\end{array}$ & Levy et al. 2015 \\
\hline$A p c^{+/-}$mice & Atg7 deficiency prevents tumor initiation and progression with Apc loss. & \\
\hline $\begin{array}{l}\text { Tumors: } \\
A p c^{-/-}\end{array}$ & $\begin{array}{l}\text { Atg7 deficiency promotes microbiota imbalance and activates an anti-tumor } \\
\text { innate immune response. }\end{array}$ & \\
\hline $\operatorname{Atg} 7^{+/+}$or $\operatorname{Atg} 7^{-/-}$ & $\begin{array}{l}\text { Atg7 deficiency activates an anti-tumor T-cell response, and T-cell ablation } \\
\text { restores tumorigenesis with Apc and Atg7 deficiency. } \\
\text { Autophagy promotes initiation and progression of intestinal cancer } \\
\text { Autophagy inhibition may prevent colon cancer. }\end{array}$ & \\
\hline $\begin{array}{l}\text { Prostate epithelium: Nkx3.1- } \\
\text { Cre tumors: } \\
\text { Pten }^{+/+}, \text {Pten }^{+/-} \text {, or Pten } \\
\text { Atg } 7^{+/+} \text {or Atg } 7^{-/-}\end{array}$ & $\begin{array}{l}\text { Pten tumor suppressor loss promotes prostate tumorigenesis. } \\
\text { Atg7 deficiency suppresses growth of Pten-deficient prostate cancer. } \\
\text { Atg7 deficiency increases endoplasmic reticulum stress in tumors and } \\
\text { reduces tumor cell proliferation. } \\
\text { Overall survival is increased by Atg7 deficiency. } \\
\text { Castrate-resistant disease is also suppressed by Atg7 loss. } \\
\text { Autophagy promotes growth of prostate cancer, and autophagy inhibition } \\
\text { may suppress prostate cancer. }\end{array}$ & $\begin{array}{l}\text { Santanam et al. } \\
2016\end{array}$ \\
\hline $\begin{array}{l}\text { Glial cells: } \\
\text { Retroviral delivery of } \mathrm{Kras}^{\mathrm{G} 12 \mathrm{D}} \\
\text { tumors: } \\
\text { Kras }{ }^{\mathrm{G}} \text { D } \\
\text { shRNA to Ulk1, Atg7, or Atg13 }\end{array}$ & $\begin{array}{l}\text { In the Kras-driven glioblastoma RCAS mouse model, shRNA to Ulk1, Atg7, } \\
\text { or Atg13 suppresses tumor growth and extends mouse survival. } \\
\text { Cells with shRNA to Ulk1, Atg7, or Atg13 are unable to maintain active } \\
\text { growth signaling under growth-restrictive conditions. } \\
\text { shRNA to Ulk1, Atg7, or Atg13 promotes senescence. } \\
\text { Autophagy is crucial for glioma initiation and growth. }\end{array}$ & $\begin{array}{l}\text { Gammoh et al. } \\
2016\end{array}$ \\
\hline $\begin{array}{l}\text { Mouse: } \\
\text { UBC_Cre-ERT2 } \\
\text { Atg } 7^{+/+} \text {or } A \operatorname{tg} 7^{-/-} \\
\text {Lung: adenovirus-FlpO tumors: } \\
\text { Kras G12D } \\
\text { p53 }\end{array}$ & $\begin{array}{l}\text { Conditional, systemic Atg7 ablation in adult mice induces selective tissue } \\
\text { damage and death predominately due to neurodegeneration 2-3 mo after } \\
\text { deletion. } \\
\text { Atg7 ablated mice are intolerant to fasting. } \\
\text { Conditional, systemic Atg7 ablation prior to Kras-driven, p53-deficient lung } \\
\text { tumor induction does not affect the efficiency of tumor initiation. } \\
\text { Conditional, systemic Atg7 ablation in mice with established Kras-driven, } \\
\text { p53-deficient lung tumors produces substantial tumor regression. } \\
\text { Whole-body Atg7 deficiency has greater anti-tumor activity than tumor- } \\
\text { specific deficiency. }\end{array}$ & $\begin{array}{l}\text { Karsli-Uzunbas } \\
\text { et al. } 2014\end{array}$ \\
\hline
\end{tabular}

macromolecules into mitochondrial metabolism to prevent AMP accumulation, energy crisis, and fatal nucleotide degradation as an attempt to remove AMP and maintain energy charge (Guo et al. 2016), analogous to what happens in yeast (Walther et al. 2010). Going forward, it will be of interest to determine whether other cancers and normal tissues similarly require autophagy for this purpose.

To address whether Atg7 is also required for lung tumorigenesis driven by different oncogenic events, it was deleted in lung tumors where Braf ${ }^{V 60 O E}$ was the oncogenic driver. Although Atg7 deficiency briefly and temporarily stimulates early tumor growth by activating NRF2, it reduces $B r a f^{V 600 E}$-driven lung tumor cell proliferation and tumor burden and prolongs mouse survival (Strohecker et al. 2013). Atg7 deficiency activates p53, which contributes to tumor suppression. Once again, p53 deletion partly relieves tumor growth impairment due to autophagy deficiency. Atg7, however, also promotes growth of Braf $^{\mathrm{V} 600 \mathrm{E}}$-driven p53-deficient lung tumors (Strohecker et al. 2013). Atg7-deficient Braf ${ }^{\mathrm{V} 600 \mathrm{E}}$-driven tumors also accumulate defective mitochondria and resemble benign oncocytomas. Again, autophagy defects cause metabolic impairment manifested by increased oxidative stress, defective mitochondrial respiration, sensitivity to starvation, and glutamine dependence (Strohecker et al. 2013). This suggests that autophagy may supply mitochondrial substrates to maintain lung tumor metabolism similar to Kras-driven lung cancers and that autophagy inhibition may have clinical utility. 


\section{Breast cancer}

Impaired autophagy caused by monoallelic loss of Becn1 suppresses Palb2-associated mammary tumorigenesis when $p 53$ is wild type but not when it is deleted (Huo et al. 2013). This indicates that autophagy facilitates cell survival and tumorigenesis upon loss of a hereditary breast cancer susceptibility gene and that this is due to promotion of p53 activation (Huo et al. 2013). Partial, rather than complete, loss of autophagy in the setting of defective DNA repair and oxidative stress may be sufficient to activate p53, limiting tumorigenesis. Complete loss of autophagy, as demonstrated by other models, may be necessary to suppress tumorigenesis with total loss of p53 function. Nonetheless this suggests that partial suppression of autophagy may delay the onset of hereditary breast cancer and that this may be a cancer prevention strategy in a high-risk population.

FIP200 is an essential autophagy protein that functions in the ULK1/Atg13/FIP200/ATG101 complex to initiate autophagosome formation as described above. FIP200 deficiency in polyoma middle $\mathrm{T}$ antigen (PyMT)-driven mammary cancer suppresses tumor growth and prolongs mouse survival (Wei et al. 2011). Similarly, disruption of autophagy by FIP200 deletion in established tumors from transformed mouse embryonic fibroblasts (MEFs) and PyMT-driven mammary tumors blocked their growth in vivo (Wei et al. 2014). FIP200 loss in mammary tumors activates an immune response, interferon production, and lymphocyte infiltration, and T-cell depletion partly restores the growth of FIP200-deficient tumors. This suggests that targeting FIP200 or other components of the autophagy initiation complex may suppress breast cancer by activating innate and adaptive anti-tumor immune responses. Interestingly, ablation of FIP200 also diminished the tumor-initiating properties of both aldehyde dehydrogenase-positive $\left(\mathrm{ALDH}^{+}\right)$and $\mathrm{CD} 29^{\text {hi }}{ }^{\mathrm{CD}} 61^{+}$breast cancer stem cells by impairing different intracellular signaling pathways (Yeo et al. 2016).

\section{Pancreas cancer}

Several years ago, it was demonstrated that pancreatic cancers have elevated levels of basal autophagy (Yang et al. 2011). Initial studies showed that these tumors required autophagy for optimal proliferation in vitro and in vivo. Autophagy inhibition either pharmacologically or genetically using RNAi impacted mitochondrial metabolism and caused increased ROS (Yang et al. 2011). An autochthonous model of Kras-driven pancreatic cancer with heterozygous, conditional deletion of p53 was crossed to a conditional Atg5 allele to study the impact of autophagy deficiency on pancreatic cancer initiation and progression. Interestingly, autophagy loss increased the initiation of premalignant PanIN lesions (Yang et al. 2014). Autophagy loss likely promotes inflammation as described above, which engenders the PanIN lesion, and a possible mechanism for this has been proposed recently (Yang et al. 2016). In a mouse model of cerulein-induced pancreatitis, loss of autophagy promoted increased activa- tion of the IкB kinase (IKK)-related kinase TBK1, neutrophil and T-cell infiltration, and PD-L1 expression. Despite promoting PanIN, autophagy deficiency significantly impaired the progression to invasive pancreatic ductal adenocarcinoma (PDAC) (Yang et al. 2014). Similar results were obtained in another Kras-driven model with either Atg5 or Atg7 deletion. However, in this case, when p53 was deleted homozygously with Kras activation and autophagy loss, the result was paradoxically increased tumor growth (Rosenfeldt et al. 2013). These conflicting findings are explained by the fact that when both copies of p53 are simultaneously deleted during embryogenesis, these tumors form without ever having p53 present, a nonphysiological situation (Amaravadi and Debnath 2014). In the setting of the heterozygous p53 genotype, the stepwise progression from PanIN to cancer reflects a more physiological context to understand the role of autophagy loss. Indeed, p53 has been shown to play a role in a transcriptional program that activated multiple autophagy genes (Crighton et al. 2006; Guo et al. 2013b; Kenzelmann Broz et al. 2013; White 2016). In the p53 heterozygous model, where autophagy loss impaired PDAC progression, the second copy of p53 is lost during tumor progression by loss of heterozygosity (LOH), which is analogous to the situation in human tumors (Yang et al. 2014).

\section{Melanoma}

Melanomas have a high level of basal autophagosomes suggestive of increased autophagy. Patients with melanoma with higher levels of autophagosomes had decreased survival (Ma et al. 2011). BRAF mutations are common in melanoma, occurring in $80 \%-90 \%$ of cases. BRAF targeted therapy results in a transient response in some patients with BRAF mutant melanoma, only to relapse shortly thereafter. To test the functional importance of autophagy in Braf ${ }^{V 600 E}$-driven melanoma, Atg7 was deleted or not in a Braf ${ }^{V 600 E}$ GEMM with and without codeletion of Pten, which is a commonly deleted gene in melanoma. Atg7 deficiency prevents melanoma development upon Braf ${ }^{V 600 E}$ activation and allelic loss of Pten (Xie et al. 2015). Atg7 deficiency also reduces Braf ${ }^{V 600 E_{-}}$ driven, Pten-deficient melanoma initiation and proliferation and greatly prolongs mouse survival (Xie et al. 2015). Although the mechanism by which Atg7 promotes the growth of melanoma is not firmly established, Atg7 prevents oxidative stress, apoptosis, fibrosis, and, notably, senescence, a known barrier to melanoma growth and progression (Xie et al. 2015). Atg7 also suppresses immune cell infiltration and cytokine production, and, given the important role of restoring the immune response in successful melanoma therapy (Lo and Fisher 2014), this should be investigated further.

\section{Colorectal cancer (CRC)}

Another cancer in which autophagy plays a promoting role is in CRC. Adenomatous polyposis coli $(A p c)$ tumor suppressor loss activates autophagy and tumorigenesis in the intestinal epithelium. Atg7 deficiency prevents 
tumor initiation and progression with Apc loss (Levy et al. 2015). Atg7 deficiency causes microbiota imbalance and activates an anti-tumor innate immune response. These Atg7-deficient tumors cause activation of an anti-tumor $\mathrm{T}$-cell response, and T-cell ablation restores CRC tumorigenesis with Apc and Atg7 deficiency (Levy et al. 2015). Thus, autophagy promotes initiation and progression of intestinal cancer driven by $A p c$ loss in mice. This suggests that autophagy inhibition could be considered for cancer prevention in those individuals with susceptibility to CRC. It will be interesting to explore whether enhanced p53 activation induced by deficient autophagy contributes to anti-tumor activity here as in other models.

\section{Prostate cancer}

Pten loss occurs with high frequency in human prostate cancer. In a GEMM for castrate-naïve prostate cancer driven by Pten deficiency, Atg7 deficiency suppresses tumor growth (Santanam et al. 2016). Atg7 deficiency increases endoplasmic reticulum stress and reduces tumor cell proliferation. Importantly, overall mouse survival is increased by Atg7 deficiency in prostate tumors, and castrate-resistant disease is also suppressed by Atg7 loss (Santanam et al. 2016).

\section{Glioblastoma}

In an avian retrovirus (RCAS)-based endogenous mouse model of Kras-driven glioblastoma, shRNA to Ulk1, Atg7, or Atg13 suppresses tumor initiation and growth, promotes senescence, and extends mouse survival (Gammoh et al. 2016). Knockdown of Ulk1, Atg7, or Atg13 in this model prevents growth under nutrient-restrictive conditions. These results demonstrate that autophagy is crucial for both glioma initiation and sustained growth and is a promising therapeutic target for glioblastoma treatment. It will be interesting to investigate why autophagy is required for both tumor initiation and growth in this setting, while it is required for tumor maintenance in others. For example, autophagy is dispensable for tumor initiation and important for tumor maintenance in Kras- and Braf-driven lung cancer (Guo et al. 2013a; Strohecker et al. 2013; Karsli-Uzunbas et al. 2014).

\section{Therapeutic window for autophagy inhibition}

The GEMMs described above provide many examples where autophagy inactivation in tumor cells in vivo can suppress tumor initiation, growth, survival, maintenance, and malignancy. As autophagy is also important for the function of normal tissues, an important question is whether tumors are more autophagy-dependent than normal tissues to an extent sufficient to provide a therapeutic window. To address this question, autophagy was ablated in adult mice through systemic, conditional deletion of Atg7. In contrast to constitutive deletion of Atg7 or Atg5, which causes neonatal lethality following loss of placental nutrition from the wild-type mother (Kuma et al. 2004; Komatsu et al. 2005), adult mice survive Atg7 deficiency for 2-3 mo (Karsli-Uzunbas et al. 2014). Loss of adipose tissue occurs early after deletion of Atg7 in adult mice, possibly due to accumulation of mitochondria and increased FAO. Later, Atg7-deleted adult mice display liver, pancreas, muscle, and kidney damage and testicular degeneration, with the majority of the mice dying from neurodegeneration (Karsli-Uzunbas et al. 2014). Other tissues (e.g., lung) are surprisingly unaffected. Thus, adult mice are less autophagy-dependent than neonates, which may reflect differences in states of tissue differentiation and metabolic demand. Although adult mice are able to tolerate systemic Atg7 ablation in the short term, they are exquisitely sensitive to starvation, as fasting the Atg7-ablated mice causes rapid death due to hypoglycemia (Karsli-Uzunbas et al. 2014). Why some tissues (e.g., brain) are more autophagy-dependent than others (e.g., lung) is an interesting question.

With this understanding of the role of autophagy in adult mice, the next point to address is whether spontaneously arising tumors are more sensitive to conditional, systemic autophagy ablation than most normal tissues. Initiation of Kras-driven, p53-deficient lung tumorigenesis is surprisingly unaffected by the systemic absence of Atg7 in mice (Karsli-Uzunbas et al. 2014). Apparently, oncogenic signaling by Kras in the absence of p53 does not require autophagy to initiate tumor formation. In contrast, systemic Atg7 conditional deletion in mice with established Kras-driven, p53-deficient NSCLC (i.e., Atg7 deletion in both the host mouse and tumor) causes striking tumor regression (Karsli-Uzunbas et al. 2014). The anti-tumor activity of systemic, conditional Atg7 deletion is surprisingly greater than Atg7 deletion only in the tumor cells (Guo et al. 2013a), suggesting a role for host autophagy as well as tumor cell-autonomous autophagy in tumor maintenance (Karsli-Uzunbas et al. 2014).

In summary, these findings indicate that tumors can be more autophagy-dependent than most normal tissues and that there may be a therapeutic window for autophagy inhibition for cancer therapy and prevention. Note that complete, irreversible genetic ablation of autophagy provides the example of the most extreme phenotype unlikely to be replicated by small molecule autophagy inhibitors. Models for genetically switchable ATG deficiency will be informative to assess the reversibility of an autophagy-deficient phenotype in both normal and tumor tissues. To address potential toxicities, the lack of brain penetration of an autophagy inhibitor should limit toxicity, and fasting should be avoided.

\section{New roles for autophagy identified in cancer progression}

In addition to its established roles in tumor cell survival and metabolic adaptation, more recent work suggests that autophagy promotes cellular processes that favor invasion and metastasis. Recent work has begun to reveal that autophagy more directly supports tumor cell motility and invasion via cell-autonomous pathways. Autophagy promotes the dynamic assembly and disassembly of 
cell-matrix FAs, which is essential for efficient migration. Live-cell imaging revealed that genetic autophagy inhibition reduces FA assembly and disassembly rates, thereby increasing FA lifetime. Autophagosomes primarily associate with leading-edge FAs during disassembly, suggesting that autophagy locally and directly facilitates the degradation and destabilization of cell-matrix contact sites. Autophagy is required for tumor cell motility, as autophagy inhibition results in a block to cell migration and invasion in vitro and reduces metastasis in vivo (Sharifi et al. 2016). Autophagy promotes FA disassembly, mediated by the interaction of processed LC3 with paxillin, a key FA component, and this interaction was promoted by phosphorylation of paxillin by oncogenic SRC (Sharifi et al. 2016), suggesting that autophagy promotes tumor cell migration and metastasis (Macintosh et al. 2012; Lock et al. 2014; Qiang et al. 2014; Kenific et al. 2016). Furthermore, the selective autophagy cargo receptor neighbor of BRCA1 (NBR1) is required for efficient FA disassembly in motile cells, indicating that a selective autophagy process analogous to mitophagy enables the specific turnover of adhesions during migration (Kenific et al. 2016). Further work is needed to ascertain the role of NBR1 and other selective autophagy receptors during cancer invasion and metastasis in vivo.

In a three-dimensional organotypic culture model, autophagy regulators (ATGs) promote tumor cell motility and extracellular matrix invasion by Ras transformed epithelial cells. In further support, lung metastases are attenuated upon ATG knockdown in Ras transformed breast cancer xenografts. Notably, this invasion defect in autophagy-deficient cells is completely rescued upon treatment with conditioned medium from autophagycompetent counterparts, indicating that intact autophagy is required for the elaboration of secreted proinvasive factors. Autophagy-dependent secretion of the proinvasive cytokine IL6 is one of the critical factors for invasion (Lock et al. 2014). Measurement of circulating cytokines secreted by tumor cells in an autophagy-dependent manner could be useful to gauge autophagy levels within patient tumors (Kraya et al. 2015). These studies support the idea that autophagy promotes the coordinate secretion of cytokines favoring tumor cell invasion and broach the hypothesis that autophagy may direct non-cell-autonomous functions in tumor cells as well as associated stromal constituents by impacting secretory capacity.

Along these lines, autophagy has been shown to mediate a critical metabolic cross-talk in pancreatic cancer between the epithelial tumor cells and a specialized type of tumor-associated fibroblast known as a stellate cell. In this case, it is autophagy in the stellate cells that promotes the secretion of nonessential amino acids, likely through the autophagic degradation of protein (Sousa et al. 2016). Here, alanine has a critical role, as the tumor cells take up the secreted alanine and use its carbon to fuel the TCA cycle and biosynthesize fatty acids (Sousa et al. 2016). The utilization of alanine allows other carbon sources, such as glucose, to be used for biosynthetic functions such as the synthesis of serine, which is important in multiple cancer types to provide nucleotides for rapidly dividing cells. Importantly, inhibition of autophagy selectively in the stellate cells blocks this cross-compartmental metabolism and attenuates the promotion of tumor growth in both cotransplantation assays and in vitro studies using conditioned medium from stellate cells (Sousa et al. 2016). In a related fashion, several ATGs have been uncovered to promote the efficient biogenesis and egress of exosomes, further suggesting important functions for components of the core autophagy machinery in the tumor microenvironment (Murrow et al. 2015).

Autophagy's role in tumor immunity remains controversial. While early reports suggested that chemotherapy-induced immunity in highly immunogenic mouse cancers is autophagy-dependent (Michaud et al. 2011), concern was raised that this model did not mirror clinical experience (Amaravadi 2011). More recently, the interaction between $T$ cells and natural killer cells and the tumor cells that they are engaged in killing suggests that tumor cell autophagy may serve to intercept perforin and granzyme effectors released by cytotoxic immune cells, blunting the efficacy of the anti-tumor immune response (Akalay et al. 2013; Baginska et al. 2013). Damage-associated molecular pattern molecules (DAMPS) such as highmobility box group 1 (HMGB1), which are critical regulators of inflammation, also control autophagy levels within tumor cells (Zhu et al. 2015). Finally, autophagy was shown to be critical for the development of immunosuppressive T regulatory cells (Wei et al. 2016). Taken together, these findings indicate that the role of autophagy in anti-tumor immunity may be highly context-dependent and warrants further study.

\section{Arguments against targeting the autophagy pathway in cancer}

While the studies described above provide compelling evidence that inhibiting autophagy may have value for cancer therapy, arguments can be made opposing this concept. First, inhibiting autophagy may be too toxic. While this is always an issue with drug development, the GEMMs have identified the major toxicity concerns, which are not beyond what has been encountered with other anti-cancer drugs. Moreover, small molecule inhibitors targeting the autophagy pathway are not likely to be capable of irreversible, complete target inhibition, as is the case of genetic deletion of an ATG.

Second, human cancer cell lines can be unaffected by autophagy suppression (e.g., Maycotte et al. 2014; Mandelbaum et al. 2015). Human cancer cell lines often tolerate genome-editing approaches that delete Atg genes when grown in two-dimensional (2D) culture with replete culture medium (Eng et al. 2016), which is in contrast to the findings from spontaneously arising tumors. This is not likely an argument against targeting autophagy, as even cell lines derived from tumors deleted for ATGs that display an in vivo tumor growth defect can grow normally in the nutrient-rich conditions of $2 \mathrm{D}$ culture, although they are sensitive to starvation (Guo et al. 2013a; Strohecker et al. 2013). The high-nutrient conditions of 
in vitro cell culture conditions may be inappropriate for testing the function of a pathway responsive to nutrient stress and may miss key anti-cancer effects that would be evident in the in vivo microenvironment. There may also be clonal selection, adaptation, and development of resistance mechanisms that occur during generation of human cancer cell lines selected for deletion for Atgs in vitro.

Third, while there are numerous reports showing growth defects from autophagy inhibition in transplanted tumors in immunocompromised mice, these tend to be less impressive than what is seen in autochthonous models (Eng et al. 2016). Immunocompromised mice neglect the role of autophagy defects in activating the host immune system. Indeed, a common property of autophagydeficient tumor cells is activation of innate and adaptive immune responses (Degenhardt et al. 2006; Guo et al. 2011; Mathew et al. 2014; Xie et al. 2015), which have been shown to contribute to anti-tumor activity (Wei et al. 2011; Levy et al. 2015). Moreover, the use of fastgrowing tumors and a short time frame of analysis in nude mice is not a physiological assessment of tumorigenesis and impaired metabolic stress adaptation (Eng et al. 2016), although this is a reasonable approach to demonstrate dependency on oncogenic signaling (e.g., the effect of a BRAF inhibitor on BRAF mutant tumor cells).

Last, the anti-tumor activity produced by autophagy deficiency in the GEMMs has been proposed to be attributed to autophagy defects in both tumor and normal host tissues, and it has been put forth that it is host and not tumor cell-autonomous autophagy that promotes tumor growth (Nyfeler and Eng 2016). While the data do support non-tumor cell-autonomous roles for autophagy in tumor growth, there are extensive data that also support the importance of autophagy in the tumor cells themselves. Indeed, with a singular exception (Karsli-Uzunbas et al. 2014), the recombinase in the aforementioned autochthonous models delete the essential autophagy gene with activation of the oncogene and/or deletion of the tumor suppressor gene in the tumor cell compartment. There is no normal host tissue deficient for autophagy in these models. Tissue-specific recombinase expression also does not confer Atg deletion in fibroblasts, the major tumor stromal component. In the GEMMs for lung tumorigenesis, adenovirus delivery of the recombinase activates tumorigenesis with or without Atg deletion in isolated individual lung epithelial cells, resulting in tumors surrounded by normal stroma and lung tissue. While both host autophagy and tumor cell-autonomous autophagy contribute to tumor growth, survival, and malignancy, the interplay between them needs more in depth study and does not account for the vast majority of tumor growth defects due to Atg deletion in the GEMMs.

\section{Potential therapeutic targets in the autophagy pathway}

As autophagy has a demonstrated role in promoting tumor initiation, growth, survival, maintenance, malignancy, and metastasis in varying settings, therapeutic targeting of autophagy for cancer therapy may have value. Efforts in both the pharmaceutical industry and academia have focused on the development of small molecule inhibitors targeting the components of the autophagy pathway. Here we discuss several autophagy targets for small molecule inhibition.

\section{ULK1}

Several groups have developed ATP-competitive inhibitors of ULK1 kinase (the apical kinase important for initiating autophagosome formation) that block autophagy in cells in vitro (Egan et al. 2015; Lazarus and Shokat 2015; Petherick et al. 2015). The most characterized of these started with a FAK inhibitor that potently inhibited ULK1 function (Russell et al. 2013; Egan et al. 2015). Medicinal chemistry efforts were driven by structure activity relationship (SAR) data and led to the development of the lead compound SBI-0206965, with an $\mathrm{IC}_{50}$ of $108 \mathrm{nM}$ for ULK1 kinase (Egan et al. 2015).

To determine whether this ULK-1 inhibitor attenuated autophagy in cancer cells, NSCLC tumor cells were treated with either the mTOR inhibitor AZD8055 alone to stimulate autophagy or AZD8055 in combination with SBI-0206965 (Egan et al. 2015). Cells treated with SBI0206965 and AZD8055 contained significantly fewer autophagic vacuoles than cells treated with AZD8055 alone (Egan et al. 2015), indicating that SBI-0206965 effectively inhibits autophagy in cancer cell lines. As SBI0206965 shows low-level activity against several other kinases, siRNA studies were performed testing 18 different kinases and then were treated with AZD8055 to stimulate autophagy. Only siRNA to ULK1 inhibited formation of GFP-LC3 puncta, indicating that the decrease in autophagy following SBI-0206965 treatment was due to inhibition of ULK-1 alone (Egan et al. 2015). Nutrient deprivation or an mTOR inhibitor (SBI-0206965) enhanced cellular apoptosis (Egan et al. 2015), indicating that tumor cells requiring autophagy for survival can be forced into cell death pathways through ULK-1 inhibition.

\section{Vps34 inhibitors}

Vps34 is the class III phosphotidyl inositol 3 (PI3) kinase (PIK-II) in the Beclin1 complex that produces PI3-phosphate, a lipid important for autophagosome membrane formation and vesicle trafficking. A fluorescent LC3 high-content, image-based screen identified Spautin-1 as an autophagy inhibitor (Liu et al. 2011). Spautin-1 inhibits the ubiquitin proteases USP10 and USP13, which remove ubiquitin from Beclin1. Spautin-1 suppresses deubiquitination of Beclin1, thereby promoting degradation of the Beclin1/Vps34 complex and inhibiting autophagy (Liu et al. 2011). As USPs have multiple substrates (p53 is also a substrate of USP10), the consequence of Spautin-1 activity is not directed solely against inhibiting autophagy. In turn, ATGs have autophagy-independent functions; thus, their direct targeting may affect other cellular processes. 
Another high-content screen followed by deconvolution and hit optimization led to identification of the Vps34 inhibitor SAR405 (Ronan et al. 2014). SAR405 binds the hydrophobic cleft of the active site and is highly selective for Vps34. SAR405 inhibits vesicle trafficking, autophagy, and lysosome function and has anti-proliferative and anti-tumor activity (Ronan et al. 2014). Independent high-throughput screening of compound libraries identified PIK-III, a potent and selective inhibitor of VPS34 that binds in the unique hydrophobic pocket of the active site (Dowdle et al. 2014). PIK-III inhibits autophagy in cells, causing the accumulation of autophagy substrates. Whether Vps34 is the best target in the autophagy pathway remains to be determined given its known role in multiple vesicular trafficking pathways

\section{ATG4 inhibitors}

ATG4B is the main cysteine protease that cleaves LC3 and the other ATG8 adaptor proteins, a step essential for subsequent lipidation, autophagosome association, and maturation. In silico approaches and in vitro studies identified an Atg4B inhibitor with low potency, which blocked autophagy and promoted tumor cell death (Akin et al. 2014.). In vitro assays for inhibitors of ATG4B protease activity have been developed with the potential to generate highly selective and potent inhibitors (Vezenkov et al. 2015; Xu et al. 2016).

\section{Lysosome inhibitors}

The ultimate destination for autophagy cargo is the lysosome, and inhibition of lysosome function (e.g., acidification and enzymatic degradation) blocks the culmination of autophagy as well as other lysosome-mediated functions. Chloroquine (CQ) is a 4-aminoquinoline that was used in the treatment or prevention of malaria. Numerous $\mathrm{CQ}$ derivatives, including hydroxychloroquine (HCQ), quinacrine, mefloquine, and piperoquine, are used clinically. CQ derivatives are known to accumulate in the endolysosomal compartment, resulting in deacidification, impaired lysosomal enzymatic function, and blockade of autophagic flux (Steinman et al. 1983). Other mechanisms of action have been proposed for CQ's cytotoxicity in cancer cells, including its ability to promote DNA damage at high doses (Bakkenist and Kastan 2003) and its anti-angiogenic properties related to impairment of Notch endosomal recycling (Maes et al. 2014). Many other purported mechanisms of action or candidate binding partners for CQ derivatives do not address the endolysosomal accumulation. Within the lysosome, the mechanism of action of CQ derivatives remains elusive. It is thought that it acts as a weak base that deacidifies the lysosome. However, many cancer drugs are weak bases that accumulate in lysosomes without producing autophagy inhibition as CQ does (Fu et al. 2014). One explanation is that HCQ can displace other combined drugs from the lysosome to the cytosol or nucleus, improving their intracellular bioavailability (Fu et al. 2014). An alter- native hypothesis that is being pursued is that CQ indeed has a molecular target.

A major concern with CQ is that it is not a specific inhibitor of autophagy (Eng et al. 2016). The data that support this conclusion rely on the observation that CQ often produces identical cytotoxicity in cancer cells engineered to lack key autophagy genes compared with their wild-type controls. The concern with this conclusion is that noncanonical autophagy programs such as Rab9-associated (Nishida et al. 2009) or TRIM31-associated vesicles ( $\mathrm{Ra}$ et al. 2016) can be recruited in cells deficient in canonical autophagy genes. The presence of these alternative autophagy programs implores caution to the notion that CQ's cytotoxicity must be autophagy-independent. Direct comparison of cell death observed with shATG5 knockdown versus with various doses of CQ suggests that there may be specific concentrations in each cellular context where CQ is autophagy-selective, and, beyond this concentration, autophagy-independent cytotoxicity may be at play (Amaravadi et al. 2007).

While the mechanism of action of CQ derivatives is being sorted out, it is clear these compounds, unlike many targeted therapies being developed for the treatment of cancer, can actually kill cancer cells. The fact that many of these agents are considered some of the safest and most inexpensive drugs made also adds to the need to study them further. The availability of these agents for clinical use has led to rapid translation of preclinical studies into clinical trials. The results of the first six cancer clinical trials involving HCQ in combination regimens (Barnard et al. 2014; Rangwala et al. 2014a, b; Rosenfeld et al. 2014; Vogl et al. 2014) as well as a single-agent trial (Wolpin et al. 2014) were recently published. In these studies, the highest doses of HCQ allowed by the Food and Drug Administration were needed to modulate autophagosome accumulation in peripheral blood mononuclear cells and tumor biopsies. While overall there was a low rate of severe toxicity in a very sick phase I population of patients, a few combinations produced dose-limiting toxicities, limiting the magnitude of autophagy modulation in those trials. More potent autophagy inhibitors or more sensitive tumors (either histologically classified or biomarker-identified) may result in better response rates. For instance, as described above, pancreas cancer may be especially vulnerable to CQ derivatives. One cycle of gemcitabine and HCQ delivered in the neoadjuvant setting significantly enhanced the resectability of locally advanced pancreatic cancer (Boone et al. 2015).

One example of a more potent CQ derivative that could be translated into a clinical drug in the near future is the dimeric CQ Lys01, which is a 10-fold more potent autophagy inhibitor than HCQ. Compared with HCQ, Lys05, a water-soluble salt of Lys01, more potently accumulates within and deacidifies the lysosome, resulting in impaired autophagy and tumor growth (McAfee et al. 2012). At the highest dose administered, some mice developed Paneth cell dysfunction that resembles the intestinal phenotype of mice and humans with genetic defects in the autophagy gene ATG16L1 (Cadwell et al. 2008), providing in vivo evidence that Lys05 targets autophagy. Unlike HCQ, 
significant single-agent anti-tumor activity is observed without toxicity in mice bearing xenograft tumors treated with lower doses of Lys05, establishing the therapeutic potential of this compound in cancer. However, while Lys05 is 10-fold more potent than HCQ in in vitro autophagy assays, it is cytotoxic only at micromolar concentrations in most cancer cells. Going forward, it will be of great interest to determine the precise mechanisms by which antagonizing lysosome function impedes cancer growth and survival, bearing in mind that this is not limited to effects on autophagy (White 2013).

\section{Identifying potential responders to autophagy inhibition in patient populations}

Unlike genetic mutations in oncogenes that help steer patients to specific ATP mimetic-based targeted therapy, specific mutated oncogenes identifying the tumors that would most benefit from autophagy inhibition are still evolving. Candidate biomarkers for potentially responsive tumors include those with abundant autophagosomes, hypoxic or nutrient stressed tumors, and tumors with activation of the MiT/TFE family. Based on preclinical work, Kras/p53 mutant PDAC, NSCLC, and melanoma are also a good starting point.

A defining feature of PDAC is its hypovascular and fibrotic microenvironment that promotes conditions of extreme hypoxia and nutrient deprivation (Ryan et al. 2014). PDAC cells adapt to life under limited nutrient conditions by relying on scavenging pathways for growth; namely, macropinocytosis and autophagy (Yang et al. 2011, 2014; Commisso et al. 2013; Perera and Bardeesy 2015). Importantly, both of these pathways converge on the lysosome for breakdown of scavenged material, and recent studies have shown that the lysosomal compartment is greatly expanded in PDAC cells (Perera et al. 2015). This finding suggests that increased lysosome biogenesis and function may be critical to the nutrient-scavenging program in PDAC to ensure efficient breakdown and recycling of cellular components and internalized material. The MiT/ TFE family of transcription factors (TFE3, MITF, and TFEB) (Settembre et al. 2011, 2013) are upstream regulators of autophagy and lysosome function, which confers PDAC cells with increased catabolic capacity (Perera et al. 2015).

MiT/TFE factors are subject to negative regulation via direct phosphorylation by mTORC1 (Roczniak-Ferguson et al. 2012; Settembre et al. 2012; Martina et al. 2014); that is, under nutrient-replete conditions, mTOR is activated and localized to the lysosome, where it phosphorylates and inactivates the MiT/TFE proteins. Conversely, upon starvation, mTOR is switched off, enabling nuclear translocation of unphosphorylated MiT/TFE proteins. This mechanism of regulation ensures that catabolic processes such as autophagy are suppressed under conditions of high nutrient availability, while activation of biosynthetic reactions are favored. In PDAC, the MiT/TFE proteins bypass mTORC1-mediated negative surveillance and are constitutively localized in the nucleus to activate autophagy and lysosome gene expression (Perera et al. 2015). Thus, PDAC cells have found a way to break the dichotomy between states of biosynthesis and catabolism. By doing so, they maximize growth processes associated with high mTOR activity while simultaneously benefiting from the nutrient scavenging and metabolic adaptation associated with activation of catabolic programs. Similarly, dephosphorylation of other mTORC1 substrates, such as ULK1, also promotes elevated autophagy in the context of high mTORC1 signaling (Wong et al. 2015), as described above. Thus, some tumors activate the MiT/TFE family by either genetic alteration or oncogenic signaling, and this may be a useful biomarker for patient selection for responsiveness to autophagy inhibition.

Another example of a clinically feasible biomarker that could enrich for cancers that are autophagy-dependent is the BRAF ${ }^{\mathrm{V} 600 \mathrm{E}}$ mutation. BRAF mutant cancers may be especially sensitive to autophagy inhibition when combined with BRAF inhibition. BRAF mutant pediatric glioma cells are highly dependent on autophagy (Levy et al. 2014), while BRAF wild-type gliomas are autophagy-independent (Levy and Thorburn 2012). Similar findings were found in BRAF mutant melanoma (Ma et al. 2014). Autophagy markers were up-regulated in a large subset of samples of patients treated with BRAF or BRAF and MEK inhibitors. Mechanistically, BRAF inhibitors produce cytoprotective autophagy through an intermediate unfolded protein response. Genetic inactivation of autophagy also enhances the efficacy of BRAF inhibitors in GEMMs with tumors driven by oncogenic Braf, which are especially autophagy-dependent (Strohecker et al. 2013; Xie et al. 2013; Strohecker and White 2014). This opens up the possibility that pharmacological autophagy inhibition could provide a different strategy to deal with drug resistance: Rather than targeting the same pathway a different way, an entirely different process (i.e., autophagy) is inhibited to circumvent resistance to a kinase inhibitor.

\section{Future directions}

The gap in our knowledge currently is the limited understanding of what autophagy specifically does at the molecular level and how this is influenced by tissue type, tumor genetics, and disease state. For example, recycling by autophagy is important to supply substrates for metabolism and survival of NSCLC, but is this true in other cancers and is the purpose the same? Will this inform combination therapy, especially with jointly targeting metabolism? When is protein and organelle quality control important? Are there adaptive or resistance mechanisms to autophagy inactivation? Does host autophagy promote tumor growth and, if so, how? Pancreatic stellate cells use autophagy to provide alanine to PDAC metabolism, but what about tumors that lack this abundant stromal compartment? Analogously, is there a role of host autophagy in supplying tumors with circulating nutrients? Does autophagy inhibition generally promote an anti-tumor immune response, and will it enhance 
response to checkpoint inhibitors? What are the best targets in the autophagy pathway for inhibitor development? How can autophagic flux be measured in human tissue samples? Can autophagy inhibitors delay the onset of hereditary breast cancer and CRC as the GEMM cancer models suggest as a strategy for cancer prevention? Answering these and other questions will inform our understanding of the role of catabolic processes in health and disease.

\section{Acknowledgments}

We thank Nabeel Bardeesy, Nicholas Cosford, Natalie Roy D'Amore, Jay Debnath, Chuck Dorsey, Jonathan Goodwin, JunLin Guan, Jessie Yanxiang Guo, Wade Harper, Xuejun Jiang, Vladimir Kirkin, Richard Klinghoffer, Mike Lotze, Kay Macleod, Jessica Martinsson, Janice Mehnert, Jorge Moscat, Rushika Perera, Kevin Ryan, Laura Shawver, Andrew Thorburn, and Richard Youle for critical discussions. R.A. is supported by National Institutes of Health grants R01CA169134, P01 CA114046, P30 CA016520, SPORE P50 CA174523, and R01CA198015. A.C.K is supported by National Institute of Health grants GM095567, R01CA157490, and R01CA188048 and an American Cancer Society Research Scholar grant (RSG-13-298-01-TBG). E.W. is supported by National Institute of Health grants R01CA130893, R01CA188096, R01CA193970, R01CA163591, and P30 CA72720 and the Robert Wood Johnson Foundation.

\section{References}

Abe T, Toyota M, Suzuki H, Murai M, Akino K, Ueno M, Nojima M, Yawata A, Miyakawa H, Suga T, et al. 2005. Upregulation of BNIP3 by 5-aza-2'-deoxycytidine sensitizes pancreatic cancer cells to hypoxia-mediated cell death. J Gastroenterol 40: 504-510.

Aita VM, Liang XH, Murty VV, Pincus DL, Yu W, Cayanis E, Kalachikov S, Gilliam TC, Levine B. 1999. Cloning and genomic organization of beclin 1, a candidate tumor suppressor gene on chromosome 17q21. Genomics 59: 59-65.

Akada M, Crnogorac-Jurcevic T, Lattimore S, Mahon P, Lopes R, Sunamura M, Matsuno S, Lemoine NR. 2005. Intrinsic chemoresistance to gemcitabine is associated with decreased expression of BNIP3 in pancreatic cancer. Clin Cancer Res 11: 3094-3101.

Akalay I, Janji B, Hasmim M, Noman MZ, Andre F, De Cremoux P, Bertheau P, Badoual C, Vielh P, Larsen AK, et al. 2013. Epithelial-to-mesenchymal transition and autophagy induction in breast carcinoma promote escape from T-cell-mediated lysis. Cancer Res 73: 2418-2427.

Akin D, Wang SK, Habibzadegah-Tari P, Law B, Ostrov D, Li M, Yin XM, Kim JS, Horenstein N, Dunn WA Jr. 2014. A novel ATG4B antagonist inhibits autophagy and has a negative impact on osteosarcoma tumors. Autophagy 10: 2021-2035.

Amaravadi RK. 2011. Cancer. Autophagy in tumor immunity. Science 334: 1501-1502.

Amaravadi R, Debnath J. 2014. Mouse models address key concerns regarding autophagy inhibition in cancer therapy. Cancer Discov 4: 873-875.

Amaravadi RK, Yu D, Lum JJ, Bui T, Christophorou MA, Evan GI, Thomas-Tikhonenko A, Thompson CB. 2007. Autophagy inhibition enhances therapy-induced apoptosis in a Myc-induced model of lymphoma. J Clin Invest 117: 326-336.
Baginska J, Viry E, Berchem G, Poli A, Noman MZ, van Moer K, Medves S, Zimmer J, Oudin A, Niclou SP, et al. 2013. Granzyme $\mathrm{B}$ degradation by autophagy decreases tumor cell susceptibility to natural killer-mediated lysis under hypoxia. Proc Natl Acad Sci 110: 17450-17455.

Baixauli F, Lopez-Otin C, Mittelbrunn M. 2014. Exosomes and autophagy: coordinated mechanisms for the maintenance of cellular fitness. Front Immunol 5: 403.

Bakkenist CJ, Kastan MB. 2003. DNA damage activates ATM through intermolecular autophosphorylation and dimer dissociation. Nature 421: 499-506.

Barnard RA, Wittenburg LA, Amaravadi RK, Gustafson DL, Thorburn A, Thamm DH. 2014. Phase I clinical trial and pharmacodynamic evaluation of combination hydroxychloroquine and doxorubicin treatment in pet dogs treated for spontaneously occurring lymphoma. Autophagy 10: 1415-1425.

Boone BA, Bahary N, Zureikat AH, Moser AJ, Normolle DP, Wu WC, Singhi AD, Bao P, Bartlett DL, Liotta LA, et al. 2015. Safety and biologic response of pre-operative autophagy inhibition in combination with gemcitabine in patients with pancreatic adenocarcinoma. Ann Surg Oncol 22: 4402-4410.

Cadwell K, Liu JY, Brown SL, Miyoshi H, Loh J, Lennerz JK, Kishi C, Kc W, Carrero JA, Hunt S, et al. 2008. A key role for autophagy and the autophagy gene Atg1611 in mouse and human intestinal Paneth cells. Nature 456: 259-263.

Cesari R, Martin ES, Calin GA, Pentimalli F, Bichi R, McAdams H, Trapasso F, Drusco A, Shimizu M, Masciullo V, et al. 2003. Parkin, a gene implicated in autosomal recessive juvenile parkinsonism, is a candidate tumor suppressor gene on chromosome 6q25-q27. Proc Nat1 Acad Sci 100: 5956-5961.

Chen S, Wang C, Yeo S, Liang CC, Okamoto T, Sun S, Wen J, Guan JL. 2016. Distinct roles of autophagy-dependent and -independent functions of FIP200 revealed by generation and analysis of a mutant knock-in mouse model. Genes Dev 30: 856-869.

Chourasia AH, Boland ML, Macleod KF. 2015a. Mitophagy and cancer. Cancer Metab 3: 1-11.

Chourasia AH, Tracy K, Frankenberger C, Boland ML, Sharifi MN, Drake LE, Sachleben JR, Asara JM, Locasale JW, Karczmar GS, et al. 2015b. Mitophagy defects arising from BNip3 loss promote tumor progression to metastasis. EMBO Rep 16: $1145-1163$.

Cicchini M, Chakrabarti R, Kongara S, Price S, Nahar R, Lozy F, Zhong H, Vazquez A, Kang Y, Karantza V. 2014. Autophagy regulator BECN1 suppresses mammary tumorigenesis driven by WNT1 activation and following parity. Autophagy 10: 2036-2052.

Commisso C, Davidson SM, Soydaner-Azeloglu RG, Parker SJ, Kamphorst JJ, Hackett S, Grabocka E, Nofal M, Drebin JA, Thompson CB, et al. 2013. Macropinocytosis of protein is an amino acid supply route in Ras-transformed cells. Nature 497: 633-637.

Crighton D, Wilkinson S, O'Prey J, Syed N, Smith P, Harrison PR, Gasco M, Garrone O, Crook T, Ryan KM. 2006. DRAM, a p53induced modulator of autophagy, is critical for apoptosis. Cell 126: $121-134$.

Degenhardt K, Mathew R, Beaudoin B, Bray K, Anderson D, Chen G, Mukherjee C, Shi Y, Gelinas C, Fan Y, et al. 2006. Autophagy promotes tumor cell survival and restricts necrosis, inflammation, and tumorigenesis. Cancer Cell 10: 51-64.

Dowdle WE, Nyfeler B, Nagel J, Elling RA, Liu S, Triantafellow E, Menon S, Wang Z, Honda A, Pardee G, et al. 2014. Selective VPS34 inhibitor blocks autophagy and uncovers a role for NCOA4 in ferritin degradation and iron homeostasis in vivo. Nat Cell Biol 16: 1069-1079. 
Egan DF, Chun MG, Vamos M, Zou H, Rong J, Miller CJ, Lou HJ, Raveendra-Panickar D, Yang CC, Sheffler DJ, et al. 2015. Small molecule inhibition of the autophagy kinase ULK1 and identification of ULK1 substrates. Mol Cell 59: 285-297.

Eng CH, Wang Z, Tkach D, Toral-Barza L, Ugwonali S, Liu S, Fitzgerald SL, George E, Frias E, Cochran N, et al. 2016. Macroautophagy is dispensable for growth of KRAS mutant tumors and chloroquine efficacy. Proc Natl Acad Sci 113: 182-187.

Erkan M, Kleef J, Esposito I, Giese T, Ketterer K, Buchler MW, Giese NA, Friess H. 2005. Loss of BNIP3 expression is a late event in pancreatic cancer contributing to chemoresistance and worsened prognosis. Oncogene 24: 4421-4432.

Ferguson SM. 2015. Beyond indigestion: emerging roles for lysosome-based signaling in human disease. Curr Opin Cell Biol 35: 59-68.

Fu D, Zhou J, Zhu WS, Manley PW, Wang YK, Hood T, Wylie A, Xie XS. 2014. Imaging the intracellular distribution of tyrosine kinase inhibitors in living cells with quantitative hyperspectral stimulated Raman scattering. Nat Chem 6: 614-622.

Gammoh N, Florey O, Overholtzer M, Jiang X. 2013. Interaction between FIP200 and ATG16L1 distinguishes ULK1 complexdependent and -independent autophagy. Nat Struct Mol Biol 20: 144-149.

Gammoh N, Fraser J, Puente C, Syred HM, Kang H, Ozawa T, Lam D, Acosta JC, Finch AJ, Holland E, et al. 2016. Suppression of autophagy impedes glioblastoma development and induces senescence. Autophagy 12: 1431-1439.

Gan B, Guan JL. 2008. FIP200, a key signaling node to coordinately regulate various cellular processes. Cell Signal 20: 787-794.

Ganley IG, Lam du H, Wang J, Ding X, Chen S, Jiang X. 2009. ULK1.ATG13.FIP200 complex mediates mTOR signaling and is essential for autophagy. J Biol Chem 284: 12297-12305.

Gasparre G, Romeo G, Rugolo M, Porcelli AM. 2011. Learning from oncocytic tumors: why choose inefficient mitochondria? Biochim Biophys Acta 1807: 633-642.

Glick D, Zhang W, Beaton M, Marsboom G, Gruber M, Simon MC, Hart J, Dorn GW II, Brady MJ, Macleod KF. 2012. BNip3 regulates mitochondrial function and lipid metabolism in the liver. Mol Cell Biol 32: 2570-2584.

Green DR, Levine B. 2014. To be or not to be? How selective autophagy and cell death govern cell fate. Cell 157: 65-75.

Guo JY, Chen HY, Mathew R, Fan J, Strohecker AM, Karsli-Uzunbas G, Kamphorst JJ, Chen G, Lemons JM, Karantza V, et al. 2011. Activated Ras requires autophagy to maintain oxidative metabolism and tumorigenesis. Genes Dev 25: 460-470.

Guo JY, Karsli-Uzunbas G, Mathew R, Aisner SC, Kamphorst JJ, Strohecker AM, Chen G, Price S, Lu W, Teng X, et al. 2013a. Autophagy suppresses progression of K-ras-induced lung tumors to oncocytomas and maintains lipid homeostasis. Genes Dev 27: 1447-1461.

Guo JY, Xia B, White E. 2013b. Autophagy-mediated tumor promotion. Cell 155: 1216-1219.

Guo JY, Teng X, Laddha SV, Ma S, Van Nostrand SC, Yang Y, Khor S, Chan CS, Rabinowitz JD, White E. 2016. Autophagy provides metabolic substrates to maintain energy charge and nucleotide pools in Ras-driven lung cancer cells. Genes Dev 30: 1704-1717.

Hanna RA, Quinsay MN, Orogo AM, Giang K, Rikka S, Gustafsson AB. 2012. Microtubule-associated protein 1 light chain 3 (LC3) interacts with BNip3 protein to selectively remove endoplasmic reticulum and mitochondria via autophagy. I Biol Chem 287: 19094-19104.

Huo Y, Cai H, Teplova I, Bowman-Colin C, Chen G, Price S, Barnard N, Ganesan S, Karantza V, White E, et al. 2013. Autophagy opposes p53-mediated tumor barrier to facilitate tumorigenesis in a model of PALB2-associated hereditary breast cancer. Cancer Discov 3: 894-907.

Jackson EL, Willis N, Mercer K, Bronson RT, Crowley D, Montoya R, Jacks T, Tuveson DA. 2001. Analysis of lung tumor initiation and progression using conditional expression of oncogenic K-ras. Genes Dev 15: 3243-3248.

Johnson L, Mercer K, Greenbaum D, Bronson RT, Crowley D, Tuveson DA, Jacks T. 2001. Somatic activation of the K-ras oncogene causes early onset lung cancer in mice. Nature 410: $1111-1116$.

Joshi S, Tolkunov D, Aviv H, Hakimi AA, Yao M, Hsieh JJ, Ganesan S, Chan CS, White E. 2015. The genomic landscape of renal oncocytoma identifies a metabolic barrier to tumorigenesis. Cell Rep 13: 1895-1908.

Karantza-Wadsworth V, Patel S, Kravchuk O, Chen G, Mathew R, Jin S, White E. 2007. Autophagy mitigates metabolic stress and genome damage in mammary tumorigenesis. Genes Dev 21: 1621-1635.

Karsli-Uzunbas G, Guo JY, Price S, Teng X, Laddha SV, Khor S, Kalaany NY, Jacks T, Chan CS, Rabinowitz JD, et al. 2014. Autophagy is required for glucose homeostasis and lung tumor maintenance. Cancer Discov 4: 914-927.

Katsuragi Y, Ichimura Y, Komatsu M. 2015. p62/SQSTM1 functions as a signaling hub and an autophagy adaptor. FEBS $J$ 282: 4672-4678.

Kenific CM, Stehbens SJ, Goldsmith J, Leidal AM, Faure N, Ye J, Wittmann T, Debnath J. 2016. NBR1 enables autophagy-dependent focal adhesion turnover. J Cell Biol 212: 577-590.

Kenzelmann Broz D, Spano Mello S, Bieging KT, Jiang D, Dusek RL, Brady CA, Sidow A, Attardi LD. 2013. Global genomic profiling reveals an extensive p53-regulated autophagy program contributing to key p53 responses. Genes Dev 27: 1016-1031.

Komatsu M, Waguri S, Ueno T, Iwata J, Murata S, Tanida I, Ezaki J, Mizushima N, Ohsumi Y, Uchiyama Y, et al. 2005. Impairment of starvation-induced and constitutive autophagy in Atg7-deficient mice. J Cell Biol 169: 425-434.

Komatsu M, Waguri S, Koike M, Sou YS, Ueno T, Hara T, Mizushima N, Iwata J, Ezaki J, Murata S, et al. 2007. Homeostatic levels of p62 control cytoplasmic inclusion body formation in autophagy-deficient mice. Cell 131: 1149-1163.

Komatsu M, Kurokawa H, Waguri S, Taguchi K, Kobayashi A, Ichimura Y, Sou YS, Ueno I, Sakamoto A, Tong KI, et al. 2010. The selective autophagy substrate p62 activates the stress responsive transcription factor Nrf2 through inactivation of Keap1. Nat Cell Biol 12: 213-223.

Koop EA, van Laar T, van Wichen DF, de Weger RA, van der Wall E, van Diest PJ. 2009. Expression of BNIP3 in invasive breast cancer: correlations with the hypoxic response and clinicopathological features. BMC Cancer 9: 175-182.

Kraya AA, Piao S, Xu X, Zhang G, Herlyn M, Gimotty P, Levine B, Amaravadi RK, Speicher DW. 2015. Identification of secreted proteins that reflect autophagy dynamics within tumor cells. Autophagy 11: 60-74.

Ktistakis NT, Tooze SA. 2016. Digesting the expanding mechanisms of autophagy. Trends Cell Biol 26: 624-635.

Kuma A, Hatano M, Matsui M, Yamamoto A, Nakaya H, Yoshimori T, Ohsumi Y, Tokuhisa T, Mizushima N. 2004. The role of autophagy during the early neonatal starvation period. $\mathrm{Na}$ ture 432: 1032-1036.

Laddha SV, Ganesan S, Chan CS, White E. 2014. Mutational landscape of the essential autophagy gene BECN1 in human cancers. Mol Cancer Res 12: 485-490.

Lassen KG, Kuballa P, Conway KL, Patel KK, Becker CE, Peloquin JM, Villablanca EJ, Norman JM, Liu TC, Heath RJ, et al. 2014. 
Atg16L1 T300A variant decreases selective autophagy resulting in altered cytokine signaling and decreased antibacterial defense. Proc Natl Acad Sci 111: 7741-7746.

Lau A, Zheng Y, Tao S, Wang H, Whitman SA, White E, Zhang DD. 2013. Arsenic inhibits autophagic flux, activating the Nrf2-Keap1 pathway in a p62-dependent manner. Mol Cell Biol 33: 2436-2446.

Lazarus MB, Shokat KM. 2015. Discovery and structure of a new inhibitor scaffold of the autophagy initiating kinase ULK1. Bioorg Med Chem 23: 5483-5488.

Lazarou M, Sliter DA, Kane LA, Sarraf SA, Wang C, Burman JL, Sideris DP, Fogel AI, Youle RJ. 2015. The ubiquitin kinase PINK1 recruits autophagy receptors to induce mitophagy. $\mathrm{Na}$ ture 524: 309-314.

Lebovitz CB, Robertson AG, Goya R, Jones SJ, Morin RD, Marra MA, Gorski SM. 2015. Cross-cancer profiling of molecular alterations within the human autophagy interaction network. Autophagy 11: 1668-1687.

Levy JM, Thorburn A. 2012. Modulation of pediatric brain tumor autophagy and chemosensitivity. J Neurooncol 106: 281-290.

Levy JMM, Thompson JC, Griesinger AM, Amani V, Donson AM, Birks DK, Morgan MJ, Mirsky DM, Handler MH, Foreman NK, et al. 2014. Autophagy inhibition improves chemosensitivity in BRAFV600E brain tumors. Cancer Discov 4: 773-780.

Levy J, Cacheux W, Bara MA, L'Hermitte A, Lepage P, Fraudeau $M$, Trentesaux C, Lemarchand J, Durand A, Crain AM, et al. 2015. Intestinal inhibition of Atg7 prevents tumour initiation through a microbiome-influenced immune response and suppresses tumour growth. Nat Cell Biol 17: 1062-1073.

Liang XH, Jackson S, Seaman M, Brown K, Kempkes B, Hibshoosh H, Levine B. 1999. Induction of autophagy and inhibition of tumorigenesis by beclin 1. Nature 402: 672-676.

Liu J, Xia H, Kim M, Xu L, Li Y, Zhang L, Cai Y, Norberg HV, Zhang T, Furuya T, et al. 2011. Beclin1 controls the levels of p53 by regulating the deubiquitination activity of USP10 and USP13. Cell 147: 223-234.

Liu L, Feng D, Chen G, Chen M, Zheng Q, Song P, Ma Q, Zhu C, Wang R, Qi W, et al. 2012. Mitochondrial outer-membrane protein FUNDC1 mediates hypoxia-induced mitophagy in mammalian cells. Nat Cell Biol 14: 177-185.

Liu Z, Chen P, Gao H, Gu Y, Yang J, Peng H, Xu X, Wang H, Yang M, Liu X, et al. 2014. Ubiquitylation of autophagy receptor Optineurin by HACE1 activates selective autophagy for tumor suppression. Cancer Cell 26: 106-120.

Lo JA, Fisher DE. 2014. The melanoma revolution: from UV carcinogenesis to a new era in therapeutics. Science 346: 945-949.

Lock R, Kenific CM, Leidal AM, Salas E, Debnath J. 2014. Autophagy-dependent production of secreted factors facilitates oncogenic RAS-driven invasion. Cancer Discov 4: 466-479.

Ma XH, Piao S, Wang D, McAfee QW, Nathanson KL, Lum JJ, Li LZ, Amaravadi RK. 2011. Measurements of tumor cell autophagy predict invasiveness, resistance to chemotherapy, and survival in melanoma. Clin Cancer Res 17: 3478-3489.

Ma X-H, Piao S-F, Dey S, McAfee Q, Karakousis G, Villanueva J, Hart LS, Levi S, Hu J, Zhang G, et al. 2014. Targeting ER stressinduced autophagy overcomes BRAF inhibitor resistance in melanoma. J Clin Invest 124: 1406-1417.

Macintosh RL, Timpson P, Thorburn J, Anderson KI, Thorburn A, Ryan KM. 2012. Inhibition of autophagy impairs tumor cell invasion in an organotypic model. Cell Cycle 11: 2022-2029.

Maes H, Kuchnio A, Peric A, Moens S, Nys K, De Bock K, Quaegebeur A, Schoors S, Georgiadou M, Wouters J, et al. 2014. Tu- mor vessel normalization by chloroquine independent of autophagy. Cancer Cell 26: 190-206.

Mancias JD, Kimmelman AC. 2016. Mechanisms of selective autophagy in normal physiology and cancer. J Mol Biol 428: 1659-1680.

Mancias JD, Wang X, Gygi SP, Harper JW, Kimmelman AC. 2014. Quantitative proteomics identifies NCOA4 as the cargo receptor mediating ferritinophagy. Nature 509: 105-109.

Mancias JD, Pontano Vaites L, Nissim S, Biancur DE, Kim AJ, Wang X, Liu Y, Goessling W, Kimmelman AC, Harper JW. 2015. Ferritinophagy via NCOA4 is required for erythropoiesis and is regulated by iron dependent HERC2-mediated proteolysis. Elife 4: e10308.

Mandelbaum J, Rollins N, Shah P, Bowman D, Lee JY, Tayber O, Bernard H, LeRoy P, Li P, Koenig E, et al. 2015. Identification of a lung cancer cell line deficient in atg7-dependent autophagy. Autophagy doi: 10.1080/15548627.2015.1056966.

Manka D, Spicer Z, Millhorn DE. 2005. Bcl-2/Adenovirus E1B 19 $\mathrm{kDa}$ interacting protein-3 knockdown enables growth of breast cancer metastases in the lung, liver and bone. Cancer Res 65: 11689-11693.

Martina JA, Diab HI, Lishu L, Jeong AL, Patange S, Raben N, Puertollano R. 2014. The nutrient-responsive transcription factor TFE3 promotes autophagy, lysosomal biogenesis, and clearance of cellular debris. Sci Signal 7: ra9.

Mathew R, Kongara S, Beaudoin B, Karp CM, Bray K, Degenhardt K, Chen G, Jin S, White E. 2007. Autophagy suppresses tumor progression by limiting chromosomal instability. Genes DeV 21: $1367-1381$.

Mathew R, Karp CM, Beaudoin B, Vuong N, Chen G, Chen HY, Bray K, Reddy A, Bhanot G, Gelinas C, et al. 2009. Autophagy suppresses tumorigenesis through elimination of p62. Cell 137: 1062-1075.

Mathew R, Khor S, Hackett SR, Rabinowitz JD, Perlman DH, White E. 2014. Functional role of autophagy-mediated proteome remodeling in cell survival signaling and innate immunity. Mol Cell 55: 916-930.

Maycotte P, Gearheart CM, Barnard R, Aryal S, Mulcahy Levy JM, Fosmire SP, Hansen RJ, Morgan MJ, Porter CC, Gustafson DL, et al. 2014. STAT3-mediated autophagy dependence identifies subtypes of breast cancer where autophagy inhibition can be efficacious. Cancer Res 74: 2579-2590.

McAfee Q, Zhang Z, Samanta A, Levi SM, Ma XH, Piao S, Lynch JP, Uehara T, Sepulveda AR, Davis LE, et al. 2012. Autophagy inhibitor Lys05 has single-agent antitumor activity and reproduces the phenotype of a genetic autophagy deficiency. Proc Nat1 Acad Sci 109: 8253-8258.

Michaud M, Martins I, Sukkurwala AQ, Adjemian S, Ma Y, Pellegatti P, Shen S, Kepp O, Scoazec M, Mignot G, et al. 2011. Autophagy-dependent anticancer immune responses induced by chemotherapeutic agents in mice. Science 334: 1573-1577.

Mizushima N, Komatsu M. 2011. Autophagy: renovation of cells and tissues. Cell 147: 728-741.

Moscat J, Diaz-Meco MT. 2012. p62: a versatile multitasker takes on cancer. Trends Biochem Sci 37: 230-236.

Murrow L, Malhotra R, Debnath J. 2015. ATG12-ATG3 interacts with Alix to promote basal autophagic flux and late endosome function. Nat Cell Biol 17: 300-310.

Newman AC, Scholefield CL, Kemp AJ, Newman M, McIver EG, Kamal A, Wilkinson S. 2012. TBK1 kinase addiction in lung cancer cells is mediated via autophagy of Tax1bp1/Ndp52 and non-canonical NF-kB signalling. PLoS One 7: e50672.

Nishida Y, Arakawa S, Fujitani K, Yamaguchi H, Mizuta T, Kanaseki T, Komatsu M, Otsu K, Tsujimoto Y, Shimizu S. 2009. 
Discovery of Atg5/Atg7-independent alternative macroautophagy. Nature 461: 654-658.

Novak I, Kirkin V, McEwan DG, Zhang J, Wild P, Rozenknop A, Rogov V, Löhr F, Popovic D, Occhipinti A, et al. 2010. Nix is a selective autophagy receptor for mitochondrial clearance. EMBO Rep 11: 45-51.

Nyfeler B, Eng CH. 2016. Revisiting autophagy addiction of tumor cells. Autophagy 12: 1206-1207.

Okami J, Simeone DM, Logsdon CD. 2004. Silencing of the hypoxia-inducible cell death protein BNIP3 in pancreatic cancer. Cancer Res 64: 5338-5346.

Perera RM, Bardeesy N. 2015. Pancreatic cancer metabolism: breaking it down to build it back up. Cancer Discov 5: 1247-1261.

Perera RM, Stoykova S, Nicolay BN, Ross KN, Fitamant J, Boukhali M, Lengrand J, Deshpande V, Selig MK, Ferrone CR, et al. 2015. Transcriptional control of autophagy-lysosome function drives pancreatic cancer metabolism. Nature 524: 361-365.

Petherick KJ, Conway OJ, Mpamhanga C, Osborne SA, Kamal A, Saxty B, Ganley IG. 2015. Pharmacological inhibition of ULK1 kinase blocks mammalian target of rapamycin (mTOR)-dependent autophagy. J Biol Chem 290: 11376-11383.

Ponpuak M, Mandell MA, Kimura T, Chauhan S, Cleyrat C, Deretic V. 2015. Secretory autophagy. Curr Opin Cell Biol 35: 106-116.

Qiang L, Zhao B, Ming M, Wang N, He TC, Hwang S, Thorburn A, He YY. 2014. Regulation of cell proliferation and migration by p62 through stabilization of Twist1. Proc Natl Acad Sci 111: 9241-9246.

Qu X, Yu J, Bhagat G, Furuya N, Hibshoosh H, Troxel A, Rosen J, Eskelinen EL, Mizushima N, Ohsumi Y, et al. 2003. Promotion of tumorigenesis by heterozygous disruption of the beclin 1 autophagy gene. J Clin Invest 112: 1809-1820.

Ra EA, Lee TA, Won Kim S, Park A, Choi HJ, Jang I, Kang S, Hee Cheon J, Cho JW, Eun Lee J, et al. 2016. TRIM31 promotes Atg5/Atg7-independent autophagy in intestinal cells. Nat Commun 7: 11726.

Rabinowitz JD, White E. 2010. Autophagy and metabolism. Science 330: 1344-1348.

Rangwala R, Chang YC, Hu J, Algazy KM, Evans TL, Fecher LA, Schuchter LM, Torigian DA, Panosian JT, Troxel AB, et al. 2014a. Combined MTOR and autophagy inhibition: phase I trial of hydroxychloroquine and temsirolimus in patients with advanced solid tumors and melanoma. Autophagy 10: 1391-1402.

Rangwala R, Leone R, Chang YC, Fecher LA, Schuchter LM, Kramer A, Tan KS, Heitjan DF, Rodgers G, Gallagher M, et al. 2014b. Phase I trial of hydroxychloroquine with dose-intense temozolomide in patients with advanced solid tumors and melanoma. Autophagy 10: 1369-1379.

Rao S, Tortola L, Perlot T, Wirnsberger G, Novatchkova M, Nitsch R, Sykacek P, Frank L, Schramek D, Komnenovic V, et al. 2014. A dual role for autophagy in a murine model of lung cancer. Nat Commun 5: 3056.

Roczniak-Ferguson A, Petit CS, Froehlich F, Qian S, Ky J, Angarola B, Walther TC, Ferguson SM. 2012. The transcription factor TFEB links mTORC1 signaling to transcriptional control of lysosome homeostasis. Sci Signal 5: ra42.

Ronan B, Flamand O, Vescovi L, Dureuil C, Durand L, Fassy F, Bachelot MF, Lamberton A, Mathieu M, Bertrand T, et al. 2014. A highly potent and selective Vps34 inhibitor alters vesicle trafficking and autophagy. Nat Chem Biol 10: 1013-1019.

Rosenfeld MR, Ye X, Supko JG, Desideri S, Grossman SA, Brem S, Mikkelson T, Wang D, Chang YC, Hu J, et al. 2014. A phase I/
II trial of hydroxychloroquine in conjunction with radiation therapy and concurrent and adjuvant temozolomide in patients with newly diagnosed glioblastoma multiforme. Autophagy 10: 1359-1368.

Rosenfeldt MT, O'Prey J, Morton JP, Nixon C, MacKay G, Mrowinska A, Au A, Rai TS, Zheng L, Ridgway R, et al. 2013. p53 status determines the role of autophagy in pancreatic tumour development. Nature 504: 296-300.

Russell RC, Tian Y, Yuan H, Park HW, Chang YY, Kim J, Kim H, Neufeld TP, Dillin A, Guan KL. 2013. ULK1 induces autophagy by phosphorylating Beclin-1 and activating VPS34 lipid kinase. Nat Cell Biol 15: 741-750.

Ryan DP, Hong TS, Bardeesy N. 2014. Pancreatic adenocarcinoma. N Engl J Med 371: 2140-2141.

Saito T, Ichimura Y, Taguchi K, Suzuki T, Mizushima T, Takagi K, Hirose Y, Nagahashi M, Iso T, Fukutomi T, et al. 2016. p62/ Sqstm1 promotes malignancy of HCV-positive hepatocellular carcinoma through Nrf2-dependent metabolic reprogramming. Nat Commun 7: 12030.

Santanam U, Banach-Petrosky W, Abate-Shen C, Shen MM, White E, DiPaola RS. 2016. Atg7 cooperates with Pten loss to drive prostate cancer tumor growth. Genes Dev 30: 399-407.

Settembre C, Di Malta C, Polito VA, Garcia Arencibia M, Vetrini F, Erdin S, Erdin SU, Huynh T, Medina D, Colella P, et al. 2011. TFEB links autophagy to lysosomal biogenesis. Science 332: $1429-1433$.

Settembre C, Zoncu R, Medina DL, Vetrini F, Erdin S, Erdin S, Huynh T, Ferron M, Karsenty G, Vellard MC, et al. 2012. A lysosome-to-nucleus signalling mechanism senses and regulates the lysosome via mTOR and TFEB. EMBO I 31: 1095-1108.

Settembre C, Fraldi A, Medina DL, Ballabio A. 2013. Signals from the lysosome: a control centre for cellular clearance and energy metabolism. Nat Rev Mol Cell Biol 14: 283-296.

Sharifi MN, Mowers EE, Drake LE, Collier C, Chen H, Zamora M, Mui S, Macleod KF. 2016. Autophagy promotes focal adhesion disassembly and cell motility of metastatic tumor cells through the direct interaction of paxillin with LC3. Cell Rep 15: $1660-1672$.

Sousa CM, Biancur DE, Wang X, Halbrook CI, Sherman MH, Zhang L, Kremer D, Hwang RF, Witkiewicz AK, Ying H, et al. 2016. Pancreatic stellate cells support tumour metabolism through autophagic alanine secretion. Nature 536: 479-483.

Sowter HM, Ratcliffe PJ, Watson P, Greenberg AH, Harris AL. 2001. HIF1-dependent regulation of hypoxic induction of the cell death factors BNIP3 and NIX in human tumors. Cancer Res 61: 6669-6673.

Sowter HM, Ferguson M, Pym C, Watson P, Fox SB, Han C, Harris AL. 2003. Expression of the cell death genes BNip3 and Nix in ductal carcinoma in situ of the breast; correlation of BNip3 levels with necrosis and grade. J Pathol 201: 573-580.

Steinman RM, Mellman IS, Muller WA, Cohn ZA. 1983. Endocytosis and the recycling of plasma membrane. I Cell Biol 96: $1-27$.

Strohecker AM, White E. 2014. Targeting mitochondrial metabolism by inhibiting autophagy in BRAF-driven cancers. Cancer Discov 4: 766-772.

Strohecker AM, Guo JY, Karsli-Uzunbas G, Price SM, Chen GJ, Mathew R, McMahon M, White E. 2013. Autophagy sustains mitochondrial glutamine metabolism and growth of BrafV600E-driven lung tumors. Cancer Discov 3: 1272-1285.

Takamura A, Komatsu M, Hara T, Sakamoto A, Kishi C, Waguri S, Eishi Y, Hino O, Tanaka K, Mizushima N. 2011. 
Autophagy-deficient mice develop multiple liver tumors. Genes Dev 25: 795-800.

Tang H, Sebti S, Titone R, Zhou Y, Isidoro C, Ross TS, Hibshoosh H, Xiao G, Packer M, Xie Y, et al. 2015. Decreased mRNA expression in human breast cancer is associated with estrogen receptor-negative subtypes and poor prognosis. EBioMedicine 2: $255-263$.

Umemura A, He F, Taniguchi K, Nakagawa H, Yamachika S, Font-Burgada J, Zhong Z, Subramaniam S, Raghunandan S, Duran A, et al. 2016. p62, upregulated during preneoplasia, induces hepatocellular carcinogenesis by maintaining survival of stressed HCC-initiating cells. Cancer Cell 29: 935-948.

Valencia T, Kim JY, Abu-Baker S, Moscat-Pardos J, Ahn CS, Reina-Campos M, Duran A, Castilla EA, Metallo CM, DiazMeco MT, et al. 2014. Metabolic reprogramming of stromal fibroblasts through p62-mTORC1 signaling promotes inflammation and tumorigenesis. Cancer Cell 26: 121-135.

van Diest PI, Suijkerbuijk KPM, Koop EA, Weger RA, van der Wall E. 2010. Low levels of BNIP3 promoter hypermethylation in invasive breast cancer. Anal Cell Pathol 33: 175-176.

Vezenkov L, Honson NS, Kumar NS, Bosc D, Kovacic S, Nguyen TG, Pfeifer TA, Young RN. 2015. Development of fluorescent peptide substrates and assays for the key autophagy-initiating cysteine protease enzyme, ATG4B. Bioorg Med Chem 23: 3237-3247.

Vogl DT, Stadtmauer EA, Tan KS, Heitjan DF, Davis LE, Pontiggia L, Rangwala R, Piao S, Chang YC, Scott EC, et al. 2014. Combined autophagy and proteasome inhibition: a phase 1 trial of hydroxychloroquine and bortezomib in patients with relapsed/refractory myeloma. Autophagy 10: 1380-1390.

Walther T, Novo M, Rossger K, Letisse F, Loret MO, Portais JC, Francois JM. 2010. Control of ATP homeostasis during the respiro-fermentative transition in yeast. Mol Syst Biol 6: 344.

Wei H, Wei S, Gan B, Peng X, Zou W, Guan JL. 2011. Suppression of autophagy by FIP200 deletion inhibits mammary tumorigenesis. Genes Dev 25: 1510-1527.

Wei H, Wang C, Croce CM, Guan JL. 2014. p62/SQSTM1 synergizes with autophagy for tumor growth in vivo. Genes Dev 28: 1204-1216.

Wei J, Long L, Yang K, Guy C, Shrestha S, Chen Z, Wu C, Vogel P, Neale G, Green DR, et al. 2016. Autophagy enforces functional integrity of regulatory $\mathrm{T}$ cells by coupling environmental cues and metabolic homeostasis. Nat Immunol 17: 277-285.

White E. 2012. Deconvoluting the context-dependent role for autophagy in cancer. Nat Rev Cancer 12: 401-410.

White E. 2013. Exploiting the bad eating habits of Ras-driven cancers. Genes Dev 27: 2065-2071.

White E. 2016. Autophagy and p53. Cold Spring Harb Perspect Med 6: a026120.

White E, Mehnert JM, Chan CS. 2015. Autophagy, metabolism, and cancer. Clin Cancer Res 21: 5037-5046.
Wolpin BM, Rubinson DA, Wang X, Chan JA, Cleary JM, Enzinger PC, Fuchs CS, McCleary NJ, Meyerhardt JA, Ng K, et al. 2014. Phase II and pharmacodynamic study of autophagy inhibition using hydroxychloroquine in patients with metastatic pancreatic adenocarcinoma. Oncologist 19: 637-638.

Wong PM, Feng Y, Wang J, Shi R, Jiang X. 2015. Regulation of autophagy by coordinated action of $\mathrm{mTORC} 1$ and protein phosphatase 2A. Nat Commun 6: 8048.

Xie X, White EP, Mehnert JM. 2013. Coordinate autophagy and mTOR pathway inhibition enhances cell death in melanoma. PLoS One 8: e55096.

Xie X, Koh JY, Price S, White E, Mehnert JM. 2015. Atg7 overcomes senescence and promotes growth of BrafV600E-driven melanoma. Cancer Discov 5: 410-423.

Xu D, Xu Z, Han L, Liu C, Zhou Z, Qiu Z, Lin X, Tang G, Shen H, Aebi J, et al. 2016. Identification of new ATG4B inhibitors based on a novel high-throughput screening platform. I Biomol Screen doi: 10.1177/1087057116639202.

Yang S, Wang X, Contino G, Liesa M, Sahin E, Ying H, Bause A, Li Y, Stommel JM, Dell'antonio G, et al. 2011. Pancreatic cancers require autophagy for tumor growth. Genes Dev 25: 717-729.

Yang A, Rajeshkumar NV, Wang X, Yabuuchi S, Alexander BM, Chu GC, Von Hoff DD, Maitra A, Kimmelman AC. 2014. Autophagy is critical for pancreatic tumor growth and progression in tumors with p53 alterations. Cancer Discov 4: 905913.

Yang S, Imamura Y, Jenkins RW, Canadas I, Kitajima S, Aref A, Brannon A, Oki E, Castoreno A, Zhu Z, et al. 2016. Autophagy inhibition dysregulates TBK1 signaling and promotes pancreatic inflammation. Cancer Immunol Res 4: 520-530.

Yeo SK, Wen J, Chen S, Guan JL. 2016. Autophagy differentially regulates distinct breast cancer stem-like cells in murine models via EGFR/Stat3 and Tgf $\beta /$ Smad signaling. Cancer Res 76: 3397-3410.

Youle RJ, Narendra DP. 2011. Mechanisms of mitophagy. Nat Rev Mol Biol 12: 9-14.

Yue Z, Jin S, Yang C, Levine AJ, Heintz N. 2003. Beclin 1, an autophagy gene essential for early embryonic development, is a haploinsufficient tumor suppressor. Proc Natl Acad Sci 100: 15077-15082.

Zhang C, Lin M, Wu R, Wang X, Yang BG, Levine AJ, Hu W, Feng Z. 2011. Parkin, a p53 target gene, mediates the role of p53 in glucose metabolism and the Warburg effect. Proc Natl Acad Sci 108: 16259-16264.

Zhu X, Messer JS, Wang Y, Lin F, Cham CM, Chang J, Billiar TR, Lotze MT, Boone DL, Chang EB. 2015. Cytosolic HMGB1 controls the cellular autophagy/apoptosis checkpoint during inflammation. J Clin Invest 125: 1098-1110.

Zong WX, Rabinowitz JD, White E. 2016. Mitochondria and cancer. Mol Cell 61: 667-676. 


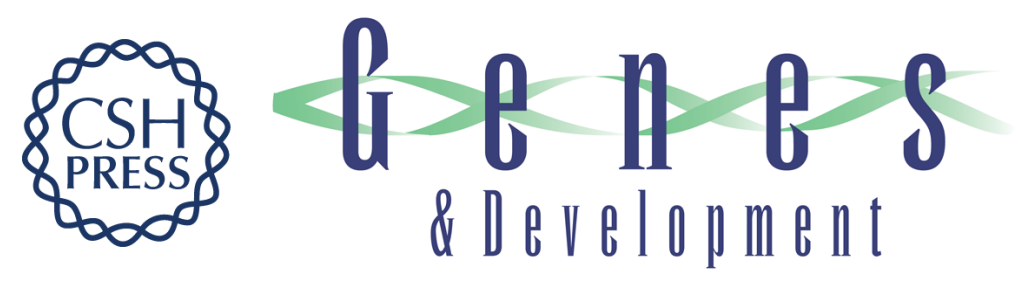

\section{Recent insights into the function of autophagy in cancer}

Ravi Amaravadi, Alec C. Kimmelman and Eileen White

Genes Dev. 2016, 30:

Access the most recent version at doi:10.1101/gad.287524.116

References This article cites 153 articles, 64 of which can be accessed free at: http://genesdev.cshlp.org/content/30/17/1913.full.html\#ref-list-1

Creative This article is distributed exclusively by Cold Spring Harbor Laboratory Press for the first Commons six months after the full-issue publication date (see License http://genesdev.cshlp.org/site/misc/terms.xhtml). After six months, it is available under a Creative Commons License (Attribution-NonCommercial 4.0 International), as described at http://creativecommons.org/licenses/by-nc/4.0/.

Email Alerting Receive free email alerts when new articles cite this article - sign up in the box at the top Service right corner of the article or click here.

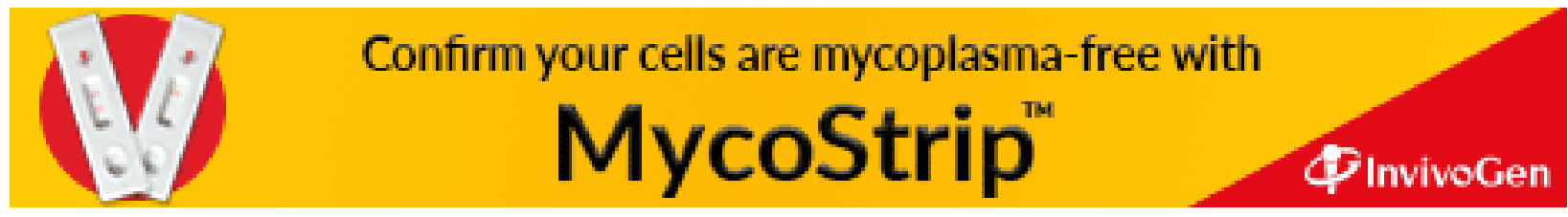

